University of Redlands

\title{
A Community Map of the University of Redlands
}

\author{
A Major Individual Project submitted in partial satisfaction of the requirements \\ for the degree of Master of Science in Geographic Information Systems \\ by \\ Rocky Bundy \\ GIS Faculty Member, Ph.D., Committee Chair \\ Second Redlands Faculty, Ph.D. \\ Other Committee Members, M.S.
}

July 30, 2012 
University of Redlands Community Campus Map

Copyright (C) 2012

by

Rocky Bundy 
The report of Rocky Bundy is approved.
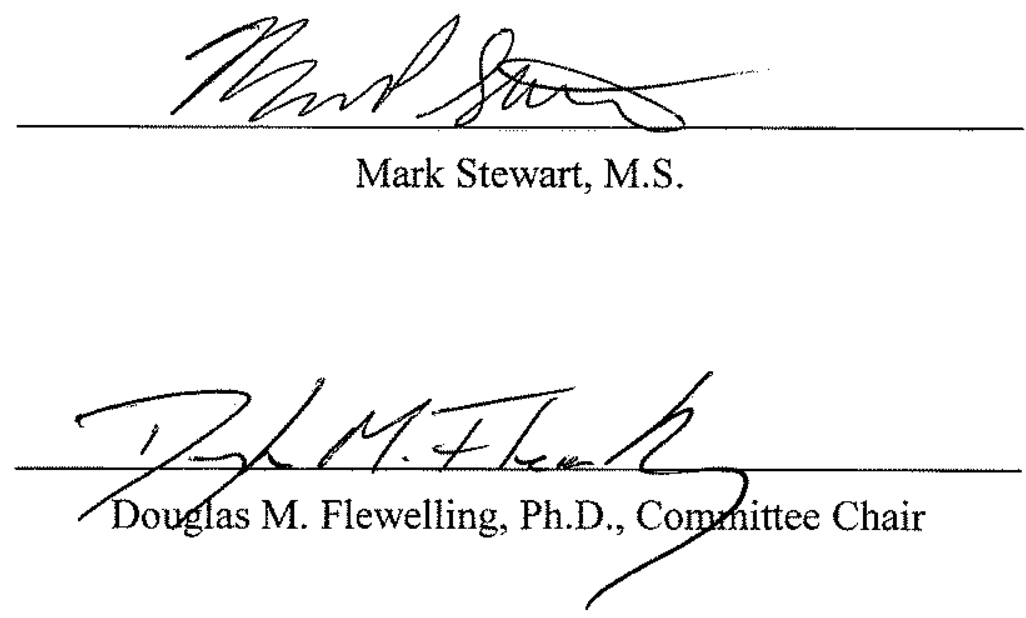

September 2012 



\section{Acknowledgements}

Pursuing a Master's Degree was never a planned achievement in my life, let alone in GIS. However, things in life are never as certain as you plan them. With that being said, there are many people that have motivated, supported, and helped me to be where I am today. I want to thank God first and foremost for the people and opportunities that he has blessed me with. Additionally, I want to thank my wife, Katie, for her unwavering support and patience. Even when I start to lose faith in my abilities, you have always said something positive and reassuring to get me going again. To my late mother, thank you for your sacrifices, discipline, and never accepting my excuses. As you worked two jobs instead of relying on welfare, you have instilled a hard work ethic in your two sons. To Mr. Terry Harshbarger, thank you for motivating me in your GEO 140 course on my very first day of college in 2003. While sitting in your roll call, I listened in amazement to your knowledge of each student's hometown or country of origin. That alone showed me the power of Geography and how knowing just a little bit of each person's culture could harness their undivided attention. To Dr. Michael Sublett, thank you for the strict teachings of your geography and Senior Seminar courses. As a prior service member myself, I appreciated your retired Army mentality and found it to be the least confusing method for geography teachings and seminar courses. I carried those expectations with all my coursework while completing my bachelor of science in geography. To the National Geospatial Intelligence Agency, thank you for the opportunity to earn a Master's Degree in GIS. I look forward to providing many more years of analysis to the agency and our US service members around the world. Finally, I would like to thank my advisor Dr. Douglas Flewelling of the University of Redlands and second advisor Mr. 
Mark Stewart. Together the two of you worked tirelessly to ensure that I stayed the course and assisted me in any and all questions sometimes requiring extended office hours. Once again, thank you everyone, I would not be here today if not for each one of your selfless contributions. 


\author{
Abstract \\ University of Redlands Community Campus Map \\ by \\ Rocky Bundy
}

The driving forces behind Esri's Community Maps program are very similar to those of all GIS users: the desire for accurate, available, transparent and cost efficient information. In an attempt to further populate the Community Maps program on ArcGIS Online, a map of the University of Redlands was produced and contributed to Esri. This topographic campus map now serves as a basemap for GIS users to use free of charge. This report explains the necessary steps in producing this campus map as well as fulfilling client and program requirements. This project will eliminate duplication efforts in data collection, layer creation and geodatabase updating, resulting in organized and current data to interested parties in performing future analysis. Although not a new concept, there is not a topographic basemap of the University of Redlands in Esri's Community Maps on ArcGIS online. 



\section{Table of Contents}

Chapter 1 - Introduction ......................................................................................... 1



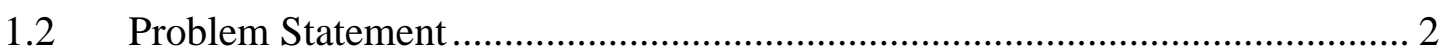

1.3 Proposed Solution ................................................................................... 2

1.3.1 Goals and Objectives ......................................................................... 3

1.3.2 Scope

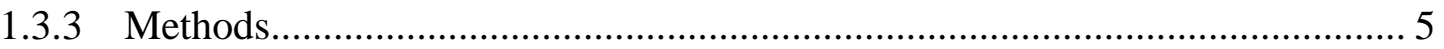

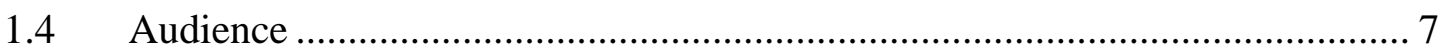

1.5 Overview of the Rest of this Report ............................................................. 7

Chapter 2 - Background and Literature Review ............................................................... 9

$2.1 \quad$ Efficiency in Resources .................................................................... 10

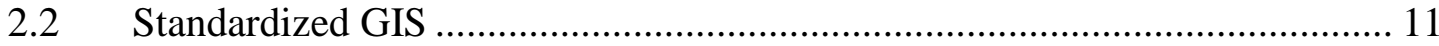



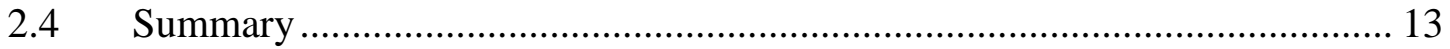

Chapter 3 - Systems Analysis and Design........................................................................... 15

3.1 Problem Statement ............................................................................ 15

3.2 Requirements Analysis ........................................................................... 15

3.2.1 Non-Functional Requirements ................................................................. 16

3.2.2 Functional Requirements (Technical) ……………....................................... 17

3.3 System Design ....................................................Error! Bookmark not defined.

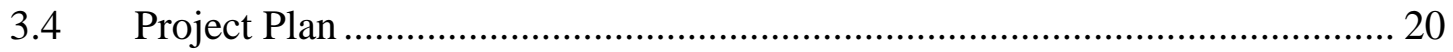




Chapter 4 - Database Design....................................................................................................... 27

4.1 Conceptual Data Model ......................................................................... 27

4.2 Logical Data Model ……………………………............................... 27

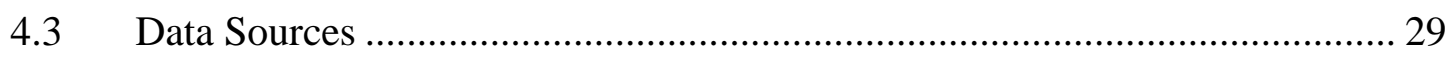

4.4 Data Collection Methods ………………………….................................. 30

4.5 Data Scrubbing and Loading ……………………................................. 30

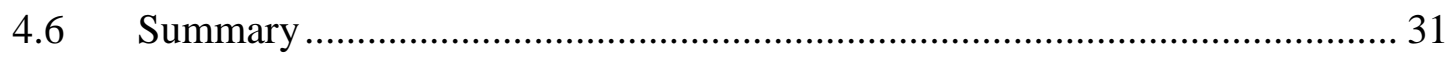

Chapter 5 - Implementation................................................................................................ 33

5.1 Esri's Community Maps Template and RI Data .............................................. 33

5.2 Feature Class Selection, Preparation, and Population …………….................. 35

5.3 Joining Attributes Between Data Sources....................................................... 47

5.4 Campus Map Quality Assurance With Minor Adjustments ............................ 48

5.5 Geodatabase Quality Assurance .............................................................. 49

5.6 Geodatabase Filter and Update Tool............................................................ 50

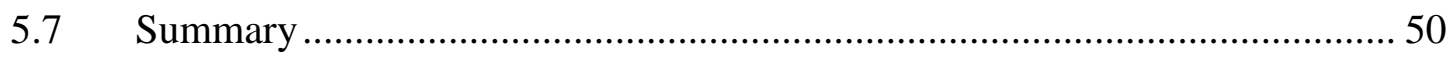

Chapter 6 - Results and Analysis.................................................................................... 51

6.1 Analysis of the RI Data and Template Data ................................................ 51

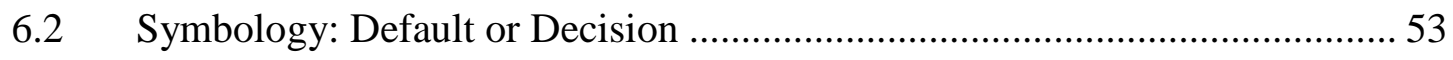

6.3 Creating Lines and Zoom Challenges......................................................... 55

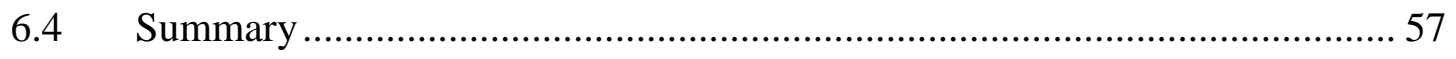

Chapter 7 - Future Works and Conclusion ....................................................................... 59

7.2 Future Work for the Redlands Institute …………………............................ 59

7.3 Future Work for the Community Maps Contribution ........................................ 61 
7.4 Conclusion

Works Cited 65

Appendix A. Important but Extraneous Information ....................................... 67 



\section{Table of Figures}

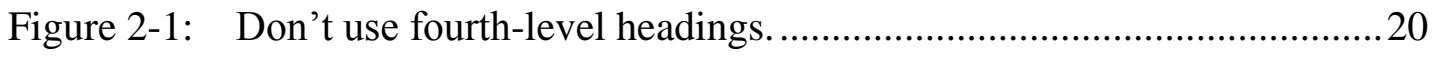





\section{List of Tables}

Table 1. Table 1. Important information in a table.........Error! Bookmark not defined. 



\section{List of Acronyms and Definitions}

$\begin{array}{ll}\text { CMP } & \text { Community Maps Program } \\ \text { GIS } & \text { Geographic Information Systems } \\ \text { Esri } & \text { Environmental Service Research Institute } \\ \text { PPGIS } & \text { Public Participation in Geographic Information Systems } \\ \text { U of R } & \text { University of Redlands } \\ \text { RI } & \text { Redlands Institute }\end{array}$





\section{Chapter 1 - Introduction}

Geographic Information Systems (GIS) users are always looking for more efficient ways produce, organize, manage, store, and deliver data and analysis. Inefficiencies such as reduplication efforts, unorganized or mismanaged data, onsite data storage limitations, and manual information delivery cost time and money. In 2010, an initiative known as the Community Maps Program (CMP) by the Environmental Service Research Institute (Esri) addressed these inefficient work practices by mapping the world with authoritative basemaps created by voluntary contributing GIS professionals from around the world. This collection of basemaps range from; county extents, downtown extents, government complexes, military bases, and even college campuses. Unfortunately, even with all these benefits, the CMP has not received the number of anticipated contributions.

Continuous contributions to the CMP could be one alternative to the inefficiencies that GIS users face when working with GIS. Once basemaps are created and contributed to the program, they are stored in Esri's cloud and eliminate the restrictions of onsite storage. These basemaps are then available for use by any GIS user who has ArcGIS 9.3 or newer, an internet connection, and access to ArcGIS Online. Ultimately, this will eliminate reduplication efforts for businesses or single GIS users needing the specified basemap. Additionally, the simplistic nature of online accessibility will provide ease of map delivery for users. This project created a University of Redlands campus map, the process of execution regarding geodatabase and map template population, and insight for future CMP contributors. 


\subsection{Client}

The client for this project was Mark Stewart of Esri in Redlands, California. Mark

Stewart is the program manager for the CMP and was interested in having a University of Redlands campus map created and contributed for use in the CMP. In addition, Mr. Stewart was interested in alternative approaches to creating this campus map while still using the provided Community Maps template.

\subsection{Problem Statement}

Professional GIS users have four primary considerations when dealing with GIS data; has the data already been created or does it exist somewhere else; storage size and location. Finally; who will access the data; and what level of accessibility does the data require. These factors all relate to resources and ultimately money. Community Maps offer a possible solution. There were three problems faced by the Community Maps Program that were addressed by the project. The first problem involved the production of a University of Redlands campus map for the CMP. The second problem detailed processes for map production and template use for explanations as to why contributions to the CMP have been as limited as they have. The last problem addressed by this project dealt with providing updates to the University of Redlands campus map geodatabase to ensure that basemaps in the Community Maps Program are updated annually for up-to-date and accurate data.

\subsection{Proposed Solution}

The proposed solution was to create a campus map of the University of Redlands for the CMP. To complete this project, a better understanding of the CMP was necessary 
together with data mining Esri's provided Local Government Template. This template will be referred to simply as "template" for the remainder of this report. Next, a collection of data was required from the Redlands Institute (RI), who possessed necessary information. This data that is provided by the RI will be referred to as "source data" for the remainder of this report. The source data included CAD files, landscape data, waterbody data, street and pavement data, and shapefiles. Source data was then used to populate the template for the creation of the campus basemap of the University of Redlands. Finally, a tool was created using model builder that filters data in the geodatabase as public or private (institutional) information. This tool then provides annual updates of the University of Redlands campus map.

\subsubsection{Goals and Objectives}

The first goal for this project was to create a campus map of the University of Redlands for contribution to the CMP. Once this campus map is authored and available for use in the CMP, users can use this basemap on ArcGIS Online. The second goal for this project if time permits, was to create a tool that will provide a filtering function and an update function in the University of Redlands campus map geodatabase for use by the RI. This tool will be used by the RI to provide annual updates to the campus map in Esri's Community Maps Program. This update is not guaranteed to be provided by the RI to the campus map, unless the RI wishes to. The tool was designed only to simplify the update process if the RI desires to do so.

The objective for this project was to encourage the RI to provide the annual updates to the $\mathrm{U}$ of $\mathrm{R}$ campus map by providing them with a simple to use tool designed to filter and update the campus geodatabase. This will assure the $\mathrm{U}$ of $\mathrm{R}$ campus data are 
as accurate as possible. Once these goals and objective were achieved, this report offered feedback to the Community Maps Program. This feedback may be used to offer suggestions in the process that may simplify procedures to the workflow or provide an explanation for the limited contributions that have been made to the program thus far.

\subsubsection{Scope}

The scope of the project included the University of Redlands. A map of the University of Redlands now benefits the CMP and the RI. This basemap satisfied the specific needs and differing criteria of the Community Maps Program and the Redlands Institute. Finally, a proposed tool was intended for creation to provide updates to the University of Redlands map and geodatabase and filters information in the geodatabase into their prospective maps. Unfortunately, time did not allow for this and further detail is expanded in Chapter 7.

The RI provided 71 different feature classes, tables, and raster datasets to this project. The use of three feature classes from this data was all that were necessary in creating the campus map. Errors in the data were not sufficient to require any additional data for the project. These three feature classes provided data on buildings, vegetation, pavement and street data, and water features. Additional data such as a campus printed map, commercial satellite imagery, CAD files, and Excel spreadsheets provided campus background information, but was not used in the creation of this campus map. Required digitizing was performed from ArcGIS Online basemap imager. ArcDesktop 10.0 was used in the development of the map, geodatabase design and model building tools. Finally, the Community Map workflow and template were provided by Esri and were 
followed to meet CMP requirements during the production of the topographic map of the University of Redlands.

Responsibilities of this project varied between the client and the project lead. Data for map creation and geodatabase organization were provided by University of Redlands. Layer requirements, template data, and workflow process came from Esri. The project lead populated the template geodatabase. The project lead planned to build the tool that updates the geodatabase and filters information in geodatabases to specified maps. Once the map and geodatabase were created, the CMP ensured that all quality checks had been met. Once completed, the final map package was given provided for uploading onto the CMP at ArcGIS online. A final map and geodatabase were packaged together and provided to Redlands Institute.

The topographic basemap of the University of Redlands was produced for the CMP on ArcGIS Online and included layers specified by the CMP template: buildings, landscape area, pavement marking lines, sidewalks, street pavement, trees, and water features.

\subsubsection{Methods}

The beginning stages of this project started with understanding the purposes and processes of community maps and the Esri's CMP. Additional research was conducted to understand Public Participation in Geographic Information Systems (PPGIS) and Volunteered Geographic Information (VGI). Knowing the differences between, the Community Maps Program, PPGIS, and VGI assured that this project would generate the specific product required among these very similar concepts. 
Once a full comprehension of the project was established, two primary data requirements were necessary. Campus data of the University of Redlands was provided by the Redlands Institute (RI) and were the building blocks used to generate the campus map. The RI campus data included building blueprints, vegetation data, pavement and street data, campus printed maps, commercial satellite imagery, CAD files, and Excel spreadsheets of campus information. However, only feature classes containing features of buildings, vegetation, pavement and street data, and water features were necessary. The second dataset were the Local Government Template and workflow for the campus map process provided by the CMP. Once the RI data was paralleled with the template, the University of Redlands Campus Map project was ready for the next step.

The software utilized for completion of this project was the ArcGIS 10 suite, which includes the three primary functions being used: ArcMap, ArcCatalog, and Model Builder. Any user of the CMP requires ArcGIS 9.3 and above. For this project ArcCatalog was used to populate the template for the University of Redlands campus map. ArcMap was used to produce the University of Redlands campus map.

Once the University of Redlands campus map was created, Model Builder was chosen to be used to generate a geodatabase tool that filters and updates the geodatabase if time permitted. This tool could have ensured that the campus map did not provide any information to the public that was determined by the $\mathrm{U}$ of $\mathrm{R}$ to be jeopardizing to their students. However, for this project, no data was provided by the RI that was considered private or institutional. This tool would be for future map generation. Finally, this campus map was contributed to Esri for use in the Community Maps Program. The geodatabase 
tool was turned over to the RI for future use or possible annual updates to the $\mathrm{U}$ of $\mathrm{R}$ campus map in Esri’s Community Maps Program.

\subsection{Audience}

The audience this report is intended for all persons who have a prior knowledge of GIS, specifically, parties who are interested in the use of basemaps, using map templates, geodatabase filtering, and update tools, the University of Redlands, Redlands Institute and the CMP at Esri. However, this report has been written so that users with little or no GIS knowledge may follow along and understand concepts. Definitions and processes have been laid out in a clear and concise manner.

\subsection{Overview of the Rest of this Report}

The subsequent chapters in this project report include Chapters 2 through Chapter 7. Chapter 2 will cover research performed during the literature review. This literature review focuses on the basemaps, campus maps, GIS standards, the CMP at Esri, Public Participation in Geographic Information Systems, and Volunteered Geographic Information. Chapter 3 discusses the system design and Chapter 4 lays out the database design. In Chapter 5, the implementation of this project is explained. Chapter 6 deliberates on the results and analysis during project completion. Finally, Chapter 7 delivers conclusions and proposes possible future work that can be done based on this project. 



\section{Chapter 2 - Background and Literature Review}

The many benefits of the Community Maps Program are very hard to ignore when deciding whether or not they are worth using or contributing to. Some of these benefits include efficiency in resources, standardized maps, and public domain access. However, before we get more involved, a basic understanding of a few key terms must be defined or explained. After this understanding of key terms, this chapter will provide detailed examples and support to the validity of using and contributing to the Community Maps Program at Esri.

The CMP at Esri began as an initiative established in 2010 to encourage public participation from the community to create authoritative basemaps. These authoritative maps are hosted on ArcGIS Online and are available for public access at no charge. The only limitations are that these maps require ArcGIS 9.3 or newer, an internet connection, and are limited to 50,000 basemaps downloads per year. These created authoritative maps are a collection of basemaps in the form of Imagery Maps, Ocean Maps, Street Maps, and Topographic Maps. But what is an authoritative map? An authoritative map is a map that is created by a person with GIS knowledge that is considered the authority of the contributing geographic location. An example of an authoritative source may be an urban planner of Rantoul, Illinois who wants to contribute a community map of Rantoul. Since the urban planner has a professional GIS background, works for the city of Rantoul, and possesses the necessary data, the urban planner is the authoritative contributor of this contributed map. This project was to create a campus map of the University of Redlands is a topographic basemap that will provide any interested party with a basemap of the campus. As a GIS student of the University of Redlands possessing data from the 
Redlands Institute, this qualified me as the authoritative source. It is important to remember that the community maps program is a collection of community contributed authoritative basemaps. These community maps are for use as basemap layers. Additional maps that are used or needed for more disciplined analysis would require the use of operational layers on a basemap not created by the CMP. This project or chapter will not discuss operational layers.

\subsection{Efficiency in Resources}

By using and participating in the CMP, there are numerous benefits in regards to efficiency. These benefits can all be best described as resource efficiency. How might the use of these community maps be viewed as efficient? Well to begin, the limit of reduplication efforts by all GIS users that possess the need for a community basemap are eliminated because a basemap has already be created. In this instance a community campus basemap of the University of Redlands has been created during this project. Because this map now exists, future users no longer need to spend time in creating a University of Redlands Campus basemap creation, as well as salary on GIS employees to recreate this map. This is the first way that the use of basemaps is efficient. Another way that these basemaps are efficient is due in part to a provided template. The provided template for community map contributors no longer have to spend as much time in decision making regarding symbology or database design. These are all created and provided for the users and contributors of the community maps program. This saved time equals saved money because what may have taken eight hours to created can now take six hours. Now, in addition to saving labor hours, GIS users can now utilized this saved time to begin new tasks or projects. 


\subsection{Standardized GIS}

Standardizing functionality with how GIS works over the years, has allowed for almost the seamless use of different GIS data. "Interoperability is the ability to communicate between systems. If a particular working environment contains an identical hardware and software configuration, the interoperability does not present a problem. However, this unified computing environment is rare in reality, particularly in GIS establishment. Many standards are about one machine talking to another. Certain types of answers are expected to come back before communications occurs. If those answers are missing, wrong or misleading, the scope or function of communication will be limited or communication may even be disabled" (United Nations, 1998). Regarding the community maps program and the ability to utilize these free basemaps, any user with ArcGIS 9.3 software or newer, along with an internet connection, has the ability to use or contribute to the program. This allows for users from all over the world to be a part of the community maps program. This ability along with constant software updates makes this an extremely powerful resource. The CMP has implemented standardizing in their templates to allow for use between GIS users and editors, while allowing for flexibility to manipulate these basemaps to fit the users needs.

\subsection{Public Domain Access}

Community Maps Data is all stored on ArcGIS Online. So, what does this mean? Simply put, all basemaps are stored in the cloud. As one could imagine, the benefits to this are exponential. To begin, all maps and data are stored in the cloud eliminating the need for storage space that the GIS user is responsible for (Stewart, M 2012). This benefit could save one tons of money in space and upkeep in regards to data storage. Another benefit to 
Public Domain Accessible data is that any user can access the data at any hour on any day of the week. This eliminates the limitation of only producing work during working hours or accessibility restrictions. A user will no longer be hindered to having their work be influenced by getting to work or IT departments dictating work schedules because of server maintenance. Tying these all together for the ultimate benefit is that this data storage, server maintenance, and full accessibility are free of charge to the user. Finally, there is one more benefit necessary to not overlook. "Beyond data sharing, the Community Maps Program is also enabling different governments and other organization to work together across administrative and physical boundaries by building data resources around common templates and requirements" (Clark and Kerski 214). This means that different parties of common interests are coming together to create ultimate maps that will benefit their needs for better community service. Fire departments and police departments can work together in providing timelier and cost effective ways when commanding emergencies. This is because they have already created a map that allows both parties to spatially depict incident command and emergency zones and better understand each other's tasks and requirements to provide public service and safety. Lastly, other map contributors are placing community maps in ArcGIS Online to showcase their capabilities and levels of data. Once a GIS user sees the amount of data, he or she may decide to go to the contributing basemap providers' website to further see what that contributor has to offer. This would be much like a window to the world to promote their data products (Kerski, J., \& Clark, J. 2012) 


\subsection{Summary}

This chapter outlined the many benefits to using and contributing to the Community Maps Program at Esri. Many of the benefits save money and resources in efficiencies.

Additionally, the standardization of GIS has helped the Community Maps Program to become widespread and available to any user possessing ArcGIS 9.3, just as the standardization of GIS has propelled many implementations of GIS and the web. Finally, the Community Maps Program provides public domain data that allows for more accessibility to data worldwide, but also promotes inter agency collaboration and mission accomplishment. In the following chapter, a systems analysis and design is discussed to provide framework for the completion of this project. 



\section{Chapter 3 - Systems Analysis and Design}

The systems analysis and design for this project focused on the creation of a University of Redlands Campus basemap for the Community Maps Program at Esri. This chapter will discuss the problem statement then provide a detailed account of functional and nonfunctional requirements necessary for the completion of this task.

\subsection{Problem Statement}

Professional GIS users often focus on three primary considerations when dealing with GIS data: has the data already been created or does it exist somewhere else; storage size and location; who will access the data; and what level of accessibility does the data require. These factors all relate to resources and, ultimately, money. Community maps offer a possible solution to these considerations. Three problems faced by the CMP were addressed in the project. The first problem involved the production of a University of Redlands campus map for the CMP. The second problem dealt with a solution in providing updates to the University of Redlands campus map geodatabase to ensure that basemaps in the CMP are updated annually for up-to-date and accurate data.

\subsection{Requirements Analysis}

A critical step for completing this project was to analyze necessary requirements. Because the CMP is used by participants worldwide, it was vital to have a clear, in depth understanding of the necessary standards for a seamless contribution and usage. The following sections will discuss in detail non-functional requirements, functional requirements (technical), and functional requirements (operational) for project completion and map contribution. These requirements were established during client 
meetings and were detailed using Use Cases, Information Product Description questionnaire forms, and routine client communication.

\subsubsection{Non-Functional Requirements}

The non-functional requirements were comprised of needs that were stated in use case assessments and information development plans. It was stated that the University of Redlands Campus Map would follow the Local Government Template that Esri requires all contributors who contribute campus maps to use. In addition to the template that laid out required layers to be represented in the campus map, a workflow was also provided to assist in processes. These layer requirements and workflow provided a very strict framework to ensure a standardized process and the assurance that all contributed maps will perform uniformly. It is worth noting that a revised template was provided at the start of the geodatabase population. There were thought to be issues with the template accepting populations into specified tables however, Esri reviewed the populated map document and determined the map had become corrupt. This determination was made over a three day turnaround and no further issues arose. Table 1 lists the functional requirements. 
Table 1. Functional Requirements

\begin{tabular}{|l|l|}
\hline \multicolumn{1}{|c|}{ Functional Requirement } & \multicolumn{1}{|c|}{ Description } \\
\hline Template Usage & Local Government Template (template) \\
\hline Workflow Usage & Community Maps optimum workflow \\
\hline Pavement/Marking Line Layer & parking lot, road marking lines, sports lines \\
\hline Sports Fields & baseball, football, softball, soccer \\
\hline Street Pavement Layer & streets, roads, allies \\
\hline Sports Courts & basketball, volleyball \\
\hline Tree Layer & tree locations \\
\hline Waterbody Layer & rivers, pools, fountains \\
\hline Building Layer & building footprint \\
\hline Landscape Area & landscaped areas \\
\hline
\end{tabular}

\subsubsection{Functional Requirements (Technical)}

Functional requirements for this project were stated in use case assessments and information development plans. The functional requirements were to provide a tool that would perform two tasks within the University of Redlands Campus Basemap geodatabase. This tool was produced using Modelbuilder in the ArcGIS 10 Desktop suite. The first task was to filter information that has been categorized as private or public 
knowledge. This data filtering ensured that only public campus knowledge would be used to produce updates to the University of Redlands Campus map in the future maintaining the privacy and safety of $\mathrm{U}$ of $\mathrm{R}$ students, faculty, and property. The second task this tool was to perform was an update function within the geodatabase for future updates to the $\mathrm{U}$ of $\mathrm{R}$ campus map. Because annual updates are preferred by the Community Maps Program, this tool would save the user time performing updates and assist in maintaining information. Table 2 lists the technical functional requirements. Two situations arose during this process of the project. The first was that no data was deemed private and therefore the creation of this tool was not a priority. This leads to the second situation during this process. Because project completion time had elapsed, the geodatabase tool was not constructed. This will be further addressed in chapter 7 .

Table 2. Non-Functional Requirements (Technical)

\begin{tabular}{|l|l|}
\hline \multicolumn{1}{|c|}{ Functional Requirement (Technical) } & \multicolumn{1}{c|}{ Description } \\
\hline ArcGIS 10 & $\begin{array}{l}\text { Esri's Arc Desktop 10 suite was used for } \\
\text { the completion of the University of } \\
\text { Redlands Campus basemap. Modelbuilder } \\
\text { was used to construct the geodatabase } \\
\text { update and filter tool. }\end{array}$ \\
\hline ArcGIS Online & $\begin{array}{l}\text { Connection capability to ArcGIS Online was } \\
\text { necessary in hosting and retrieving } \\
\text { community maps from Esri's Community } \\
\text { Maps program. }\end{array}$ \\
\hline
\end{tabular}

A change was made during the tool construction process during this project because no data deemed private were given for the construction of the U of R Campus Map or geodatabase. The end resulting tool for the University of Redlands Campus map to assist with geodatabase updates was given a last priority. Any needs for deleting fields or data 
in the geodatabase currently were left to the "Delete Field" tool in ArcToolbox.

Therefore, this tool was not provided to the Redlands Institute for future updates and made no commitment was made to Esri's Community Maps Program for annual updates.

\section{Table 3. Operational Requirements}

\begin{tabular}{|l|l|}
\hline \multicolumn{1}{|c|}{ Operational Requirement } & \multicolumn{1}{|c|}{ Description } \\
\hline Update and filter geodatabase tool & $\begin{array}{l}\text { This tool performs two primary functions. } \\
\text { The first function separated data in the } \\
\text { geodatabase that is labeled as private } \\
\text { information. The second function took the } \\
\text { filtered data and updated the geodatabase } \\
\text { with the current changes in the data. }\end{array}$ \\
\hline
\end{tabular}

\subsection{System Design}

The system detailed for this project was thoroughly laid out by Esri's Community Maps Department. The driving concept was for authoritative maps to be produced by outside contributors and stored in a community cloud at a single location for worldwide distribution. This means that contributors receive a community maps standardized template, the producer uses their own computer to produce a community map, the map is then provided to Esri to be cached, Esri stores each map in their cloud, and Esri serves these maps on ArcGIS Online. Further detail was provided by revisiting the Use Case and Information Product Description questionnaire forms.

Specific to this project, the Community Maps workflow was followed for a standard guideline. Campus data were collected from the Redlands Institute and the template was populated with its specific requirements. The geodatabase tool was initiated and the 
University of Redlands Campus map was completed and turned over to Esri's

Community Maps Program.

\subsection{Project Plan}

The project plan that outlined major tasks that were achieved during the completion of this project is detailed in this section. Each task was contingent upon the previous task; therefore quality checks occurred at the end of most tasks. The workflow diagram in Figure 3.1 is a view of the project plan broken down to understand and vision these tasks.

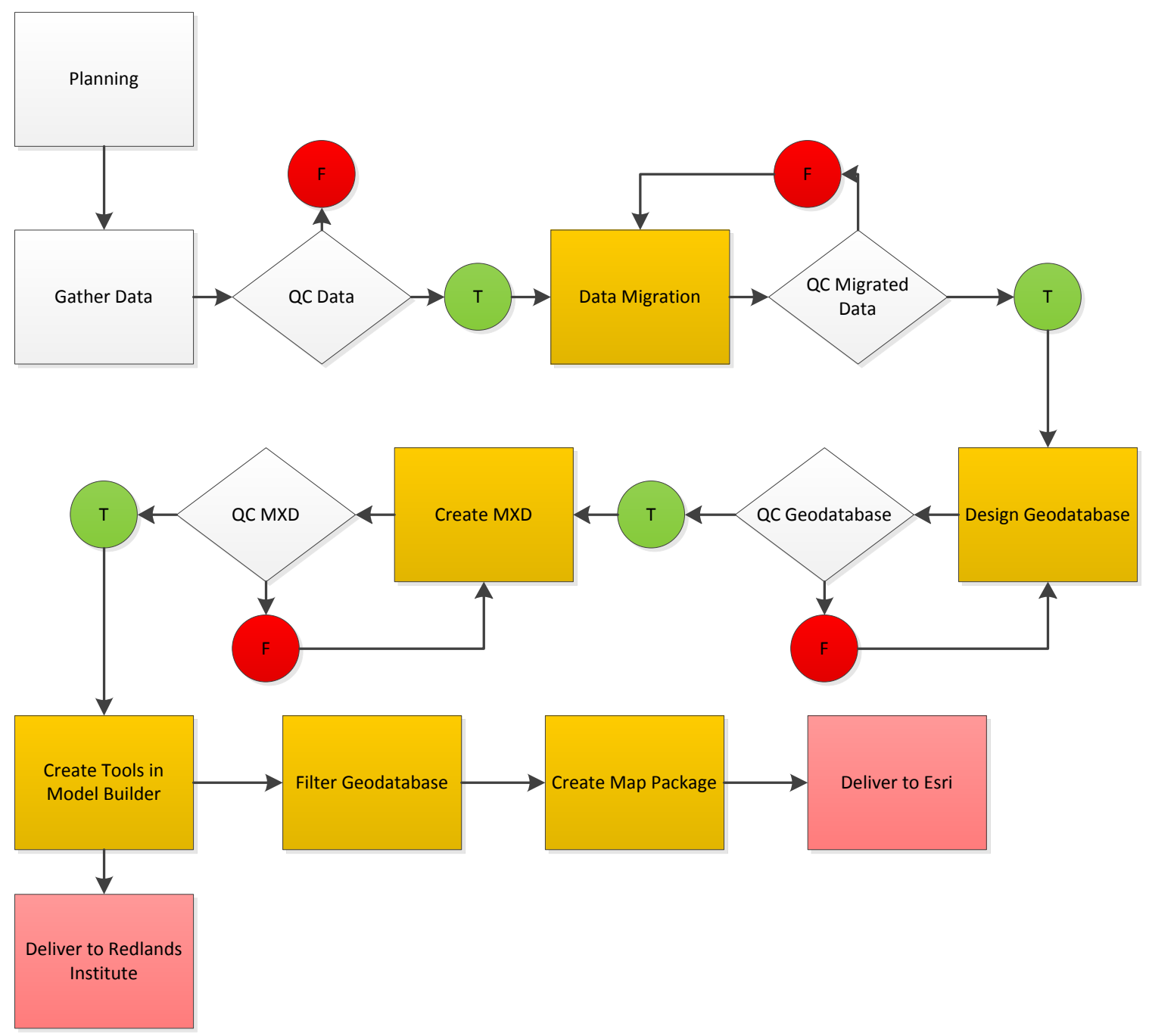

Figure 3-1: Original Project Plan. 


\section{Task 1: Planning}

The plan implemented in this project was derived from an understanding of the project requirements, geodatabase design, the needs of the Redlands Institute, and the needs of the CMP at Esri. These basic understandings provided the data structure necessary for the requirements to be fulfilled.

\section{Task 2: Gather Source Data}

Data were provided by the Redlands Institute. No additional data were necessary.

\section{Task 3: Data Migration}

Data were migrated from the University of Redlands. It was important to ensure that all data were transferred in their entirety. No additional data such, as GPS data, were necessary.

\section{Task 4: Design Geodatabase}

The geodatabase for this project was populated and edited using ArcDesktop 10.0 per the needs of Redlands Institute and project requirements. As mentioned previously, data provided from the Redlands Institute were used to populate this geodatabase. The template from Esri was used for geodatabase design.

\section{Task 5: Create MXD}

The University of Redlands map was created using ArcDesktop 10.0. This map was constructed from data provided by the Redlands Institute. The template provided from Esri was used in the construction of the map. 


\section{Task 6: Create Tools in Model Builder}

Two tools were planned for development using ModelBuilder in ArcDesktop 10.0 The first tool to be designed was to filter campus data considered too critical to release publically. Data considered too critical would be determined by the University of Redlands. Data releasable to the public was used in the production of the topographic basemap of the University of Redlands. The second tool was to be designed to perform user updates to the geodatabase and campus map. No data provided by the RI were considered private data. Therefore, the map was not created with any private data, so no filtering tool was necessary. Additionally, there have been no plans to update this map for the CMP; therefore no update tool was created for this map.

\section{Task 7: Filter Geodatabase}

Initially, thought to have the need to filter out private campus data, only public data was provided from the Redlands Institute for the completion of this project. Therefore, there was no need to filter the geodatabase of private data from public data.

\section{Task 8: Create Map Package}

Upon geodatabase population and map creation, one map package was put together. The map package was the detailed map of the University of Redlands and included the map and geodatabase. This map package was constructed for delivery to the CMP at Esri. Previously, Community Maps contributors had to cache their own maps for submission to Esri. This process of elimination simplified this task for this project. The U of R geodatabase update tool was provided to the Redlands Institute. 


\section{Task 9: Deliver}

The map package was delivered its prospective client, Mark Stewart. Mr. Stewart ensured his satisfaction with project requirements and functions.

Figure 2 shows a detailed time projection for initial project completion. As most projects, the planning stage is a valuable time to create a guide for project completion, but it is merely that, a guide and rarely do things finish the way they were constructed in the planning stage.

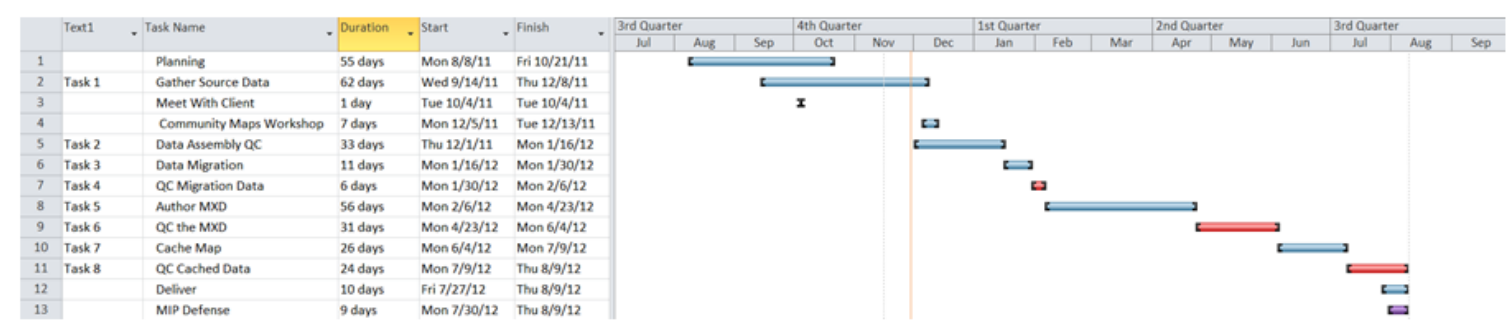

Figure 3-2: Original Time Frame.

The project underwent a several changes during its completion. As mentioned previously, the filter function in the filter/update geodatabase tool was not created because no filter function was necessary. Additionally, an idea to create 3D shapefiles representing the buildings on the $\mathrm{U}$ of $\mathrm{R}$ campus surfaced but was eventually decided against due to a lack of time. Figure 3.3 reflects the changes in the project plan. 


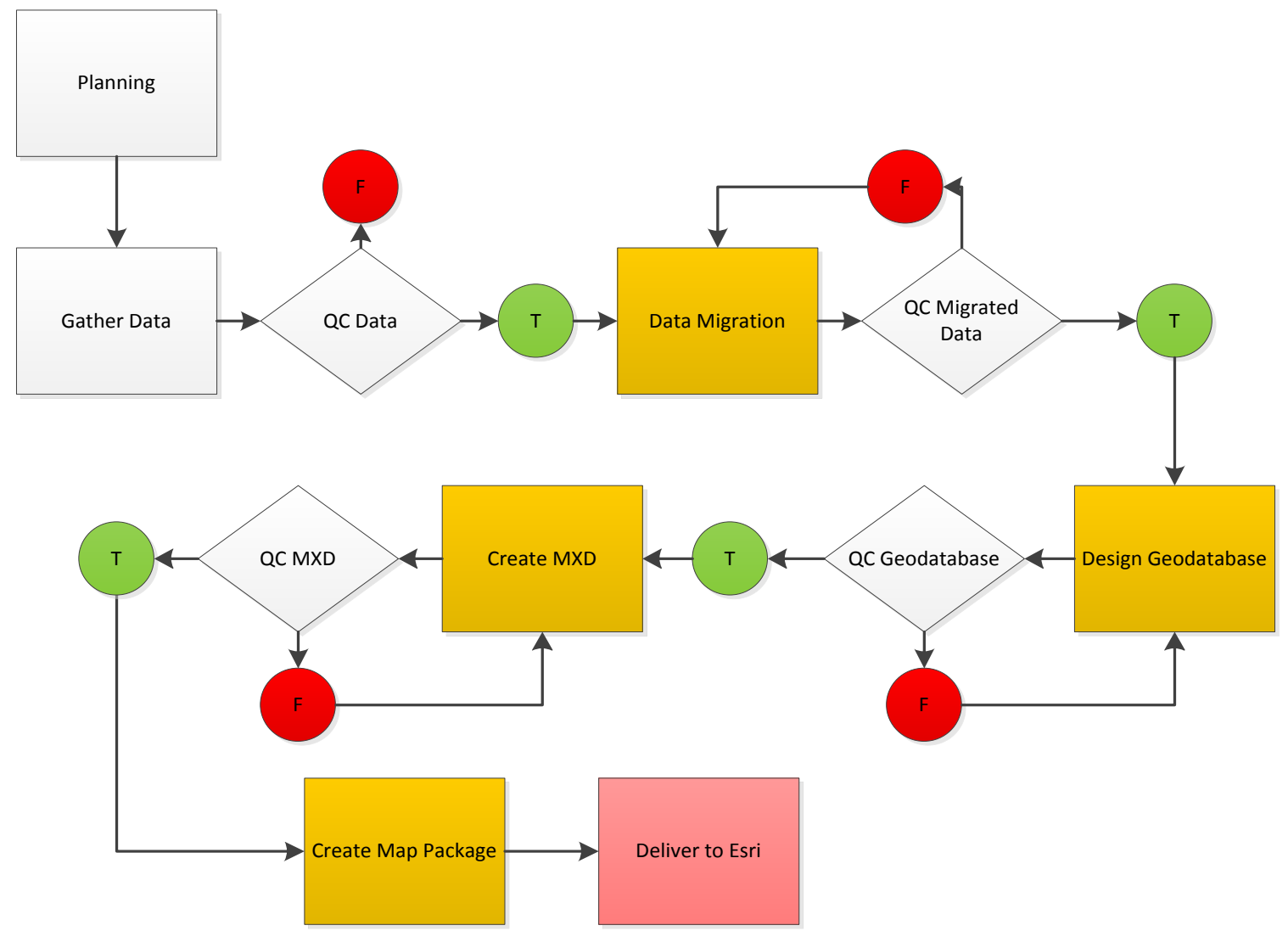

Figure 3-3: Revised Project Plan.

The new time frame seen in Figure 3.4 shows how the many changes in the workflow altered the time spent on this project. The amount of time shifted dramatically when the tool was lowered as a priority and the detailed digitizing of the campus map took precedence. 


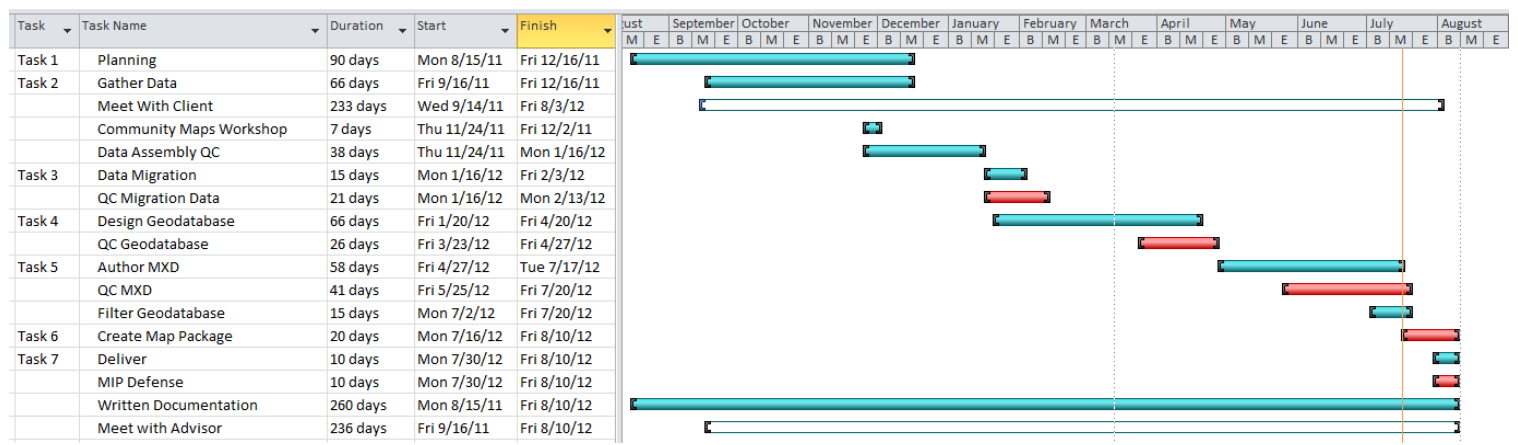

Figure 3-4: The revised project time frame.

\subsection{Summary}

The requirements analysis, system design, and project plan changed throughout the implementation of this project. Many of these changes were noted during use case assessments, Information Product Deliveries, or client meetings. This reduced the time and resources allocated in a correction process. In summary, the campus template changed minimally, the CMP no longer required the map contributor to cache their own maps, and the $\mathrm{U}$ of $\mathrm{R}$ geodatabase filter/update tool was no longer necessary to perform filter functions or update functions. 



\section{Chapter 4 - Database Design}

"GIS planning leads to GIS success, and absence in planning leads to failure."

(Tomlinson, R. 2011). So with database design is the driving force behind a successful GIS products and maps it is necessary to identify plans and necessities for a successful geodatabase. This chapter will discuss the logical data model, data sources, data collection methods, data scrubbing, future works, and conclusions. It is important to know that because a template geodatabase was provided by the Community Maps Program however, it was not necessary to detail a conceptual model before detailing a logical model in this chapter.

\subsection{Conceptual Data Model}

Again, because the Community Maps Program provided the specified template for population, there was no need for a conceptual data model. The logical data model will follow this section.

\subsection{Logical Data Model}

The geodatabase is an object-relational database model. The geodatabase is a storage container for geographic data. Datasets that are stored in the geodatabase are feature classes, attribute tables, or raster datasets (Tomlinson, R. 2011). This statement defines exactly the contents that consisted in this project. All feature classes that comprise the University of Redlands Campus map pointed back to the single feature dataset Facilities Streets in the Local Government Template Geodatabase with the exception of the waterbody feature class. This feature class pointed to the reference data feature dataset as indicated in Figure 4.1. This is not an error in the design of the geodatabase, but rather a 
remedy to recreating the geodatabase at this time. The reason for a possible redesign in the future is due in part to the fact that the Local Government Template was designed for larger scaled maps than the campus of the University of Redlands.

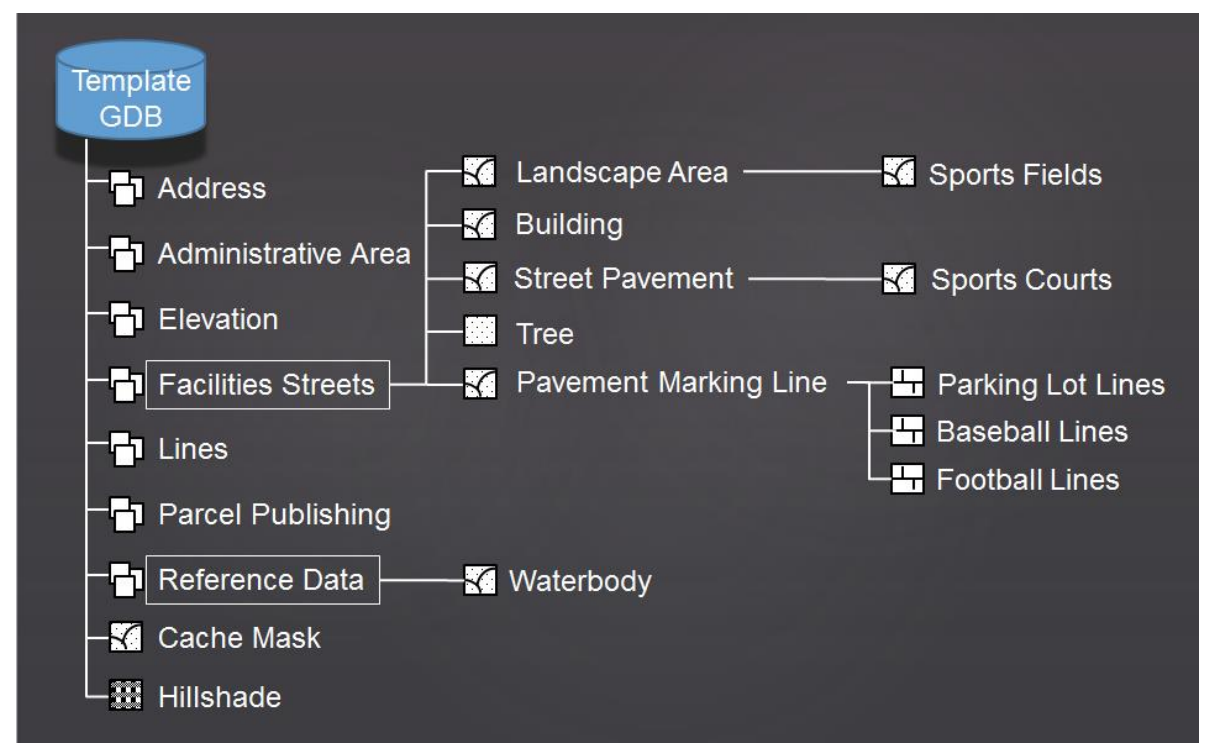

\section{Figure 4-1: The University of Redlands Campus map database layout.}

Each of the feature classes possessed attributes which required population. These attributes were populated based off the function of the feature. One example of a feature class being assigned attributes was the Landscape Area Feature Class. This consisted of vegetation that required maintenance or upkeep. Following that decision to populate a feature class named LandscapeArea; the next decision was decided if that LandscapeArea provided an additional purpose such a sport. This newly identified purpose was then populated in the attribute table as a Sports Field. This process took place for additional feature classes within the database. However, there were some instances where some feature classes did not point back to obviously applicable feature datasets. The instance in the project where Baseball Lines and Football Lines pointing to the Pavement Marking Lines Feature Class that then points back to the Facilities Streets Feature Dataset. This 
design of the geodatabase is not entirely wrong, it just was not intuitive. This is in fact a template database concern that is limited to the scale range of the template. As mentioned previously in this project, the Local Government Template is the smallest scale template currently for the Community Maps Program. With this being said the creators of this template have decided that all marking lines will point to the Pavement Marking Lines Feature Class rather than creating a new geodatabase template. This currently is the most efficient remedy to this situation.

\subsection{Data Sources}

Data sources came from two primary contributors; the CMP at Esri and the Redlands Institute. The CMP provides all contributors to their program the necessary template for their contributions. In the case of this project it was necessary to utilize the Local Government Template. This template is used to provide topographic maps to populate the CMP on ArcGIS Online. This template was the smallest scaled map template available for the University of Redlands Campus Map. This was the template data that was populated by the source data.

The second data provided for this project was the source data that populated the template data. This data, or the campus data, was provided by the RI. The Redlands Institute is a small research enterprise responsible for the creating and maintaining data for the University of Redlands. Because of this intimate relationship with the University, this qualifies the Redlands Institute as an authority in the University of Redlands regarding source data. This data satisfied the preferences of the CMP at Esri.

Metadata is commonly overlooked or simply ignored. In the case of this project, that simply is not true. The metadata was determined by two specific personnel; Mark Stewart 
of the CMP and Lisa Benvenuti of the RI. Metadata was primarily attributed by the Redlands Institute source data, therefore was simply updated by the contributor of this community campus map. Updates to existing metadata in previously created features were provided while newly created features were received new metadata. The metadata included; tags, descriptions, contact information, update request dates, and lineage. This was done during the final stages of map completion.

\subsection{Data Collection Methods}

Source data was provided by the RI. In fact, 71 different data if the form of feature classes, tables, and raster datasets were the data received for the project of creating a University of Redlands Campus basemap. However, additional data was used in this project that was not provided by the RI. The additional data was either digitized from imagery from Bing Maps provided by the CMP imagery basemaps or ground truthed from photos collected by walking the campus. Although this data does not constitute the majority of the campus map, it does provide the necessary detail the CMP prefers. With this being said, the data used for these preferences came from user provided or resourced data.

\subsection{Data Scrubbing and Loading}

As mentioned in the previous section, the RI provided 71 different data consisting of feature classes, tables, and raster datasets. This project only utilized a single feature class possessing the primary components for creation of the campus map. Unfortunately, it was not realized until multiple hour were exhausted while looking though all data provided.

One the single feature class was selected, ArcCatalog revealed that the data was produced from a single shapefile. This created an issue during the digitizing portion of the project. 
However, this was not catastrophic because the Community Maps Program does not require their contributed maps to possess topology. These maps simply provided basemaps as geographic visual reference.

One portion of the data that was not provided and required creating was parking lot lines. These lines were anticipated to be part of the parking lots feature class, but this was not the case. Therefore, this data was not entirely complete.

\subsection{Summary}

Without a carefully designed and executed Database successful GIS products and maps are unlikely to reach their desired purpose. This chapter discussed the logical data model, data sources, data collection methods, data scrubbing, future works, and finally conclusions. It is worth noting that this database design was provided and that any encounters with the database where noted and submitted to the client for future remedy. This is also noted in the future works section of this report. The following chapter will discuss the implementation of creating a campus map of the University of Redlands. 



\section{Chapter 5 - Implementation}

Chapter 5 discusses the implementation of this project and includes a review of the RI data and Esri's provided template. Data selection, preparation, migration, and template population will be addressed in the following section. The next section will address joining tables between the RI data and the template. Subsequent sections include campus map quality assurance and campus geodatabase quality assurance. Finally, this chapter will discuss the U of R Geodatabase Update Tool and how it was executed.

\subsection{Esri's Community Maps Template and RI Data}

The Community Maps Program at Esri provides different templates for their contributors. The template used for the University of Redlands Campus map was the Local Government template which possessed all required layers and symbology for the creation of this map. The template is set up to receive data immediately for map population. The Redlands Institute maintains campus data for the University of Redlands and provided campus data that included feature classes, database tables, and raster datasets of the University of Redlands. Within these data types were: buildings, vegetation, streets, parking lots, sidewalks, trees, water features, and other campus data. The RI data and the Local Government template (which is still referred to simply as "template") were meticulously reviewed before the project was taken any further. Figure 5.1 shows the template geodatabase and what layers where expected to be populated for project completion. Figure 5.2 shows the RI database and all data the Redlands Institute has maintained for the University of Redlands. 


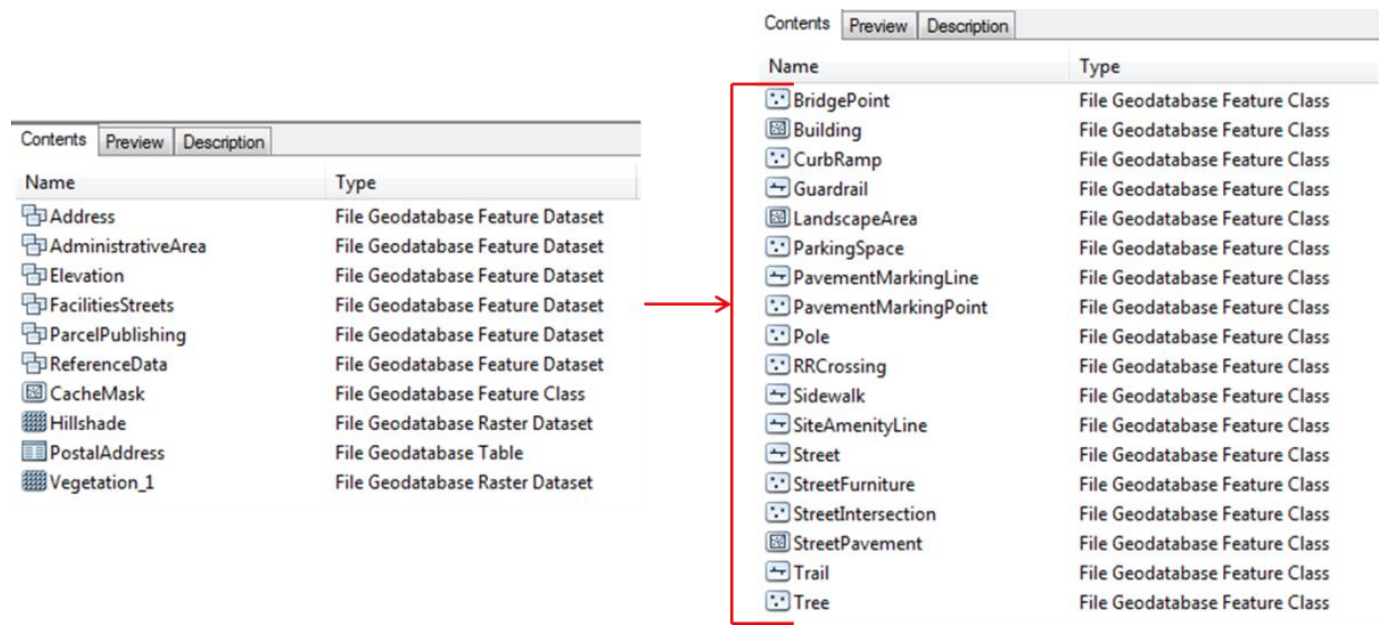

Figure 5-1: Template Geodatabase File Structure.

\begin{tabular}{|c|c|c|}
\hline \multirow{2}{*}{$\begin{array}{l}\text { Contents } \\
\text { Name }\end{array}$} & \begin{tabular}{|l|l|} 
Preview & Description \\
\end{tabular} & \multirow[b]{2}{*}{ Type } \\
\hline & & \\
\hline \multicolumn{2}{|c|}{ 国ADA2CampusFeatures_Lookup... } & File Geodatabase Table \\
\hline \multicolumn{2}{|c|}{  } & File Geodatabase Raster Dataset \\
\hline \multicolumn{2}{|c|}{ AIAERIAL_3FT_2005 } & File Geodatabase Raster Dataset \\
\hline \multicolumn{2}{|c|}{ 圇Building2LotAccess_Lookup } & File Geodatabase Table \\
\hline \multicolumn{2}{|c|}{ 国BuildingBlurbs } & File Geodatabase Table \\
\hline \multicolumn{2}{|c|}{$\because$ Campus_HandicappedParkingS... } & File Geodatabase Feature Class \\
\hline \multicolumn{2}{|c|}{$\because$ FireExtinguishers } & File Geodatabase Feature Class \\
\hline \multicolumn{2}{|c|}{ (⿴囗⿱十口⿴囗十 RedlandsCityLimits } & File Geodatabase Feature Class \\
\hline \multicolumn{2}{|c|}{$\because$ RedlandsHydrants } & File Geodatabase Feature Class \\
\hline \multicolumn{2}{|c|}{ REDLANDSRELIEF10M } & File Geodatabase Raster Dataset \\
\hline \multicolumn{2}{|c|}{ 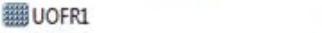 } & File Geodatabase Raster Dataset \\
\hline \multicolumn{2}{|c|}{ 피플 } & File Geodatabase Raster Dataset \\
\hline \multicolumn{2}{|c|}{ [- UoR_BrocktonApt } & File Geodatabase Feature Class \\
\hline \multicolumn{2}{|c|}{ 圆UoR_BrocktonDriveways } & File Geodatabase Feature Class \\
\hline \multicolumn{2}{|c|}{ Uor_BrocktonSprinklers } & File Geodatabase Feature Class \\
\hline \multicolumn{2}{|c|}{ 國UoR_buffer $5 \mathrm{mi}$} & File Geodatabase Feature Class \\
\hline \multicolumn{2}{|c|}{ YUoR_BuildingPoints } & File Geodatabase Feature Class \\
\hline \multicolumn{2}{|c|}{ YUor_Callbox } & File Geodatabase Feature Class \\
\hline \multicolumn{2}{|c|}{ 國UoR_Campus 2003} & File Geodatabase Feature Class \\
\hline \multicolumn{2}{|c|}{ UoR_Campus2004 } & File Geodatabase Feature Class \\
\hline \multicolumn{2}{|c|}{ UoR_Campus2005 } & File Geodatabase Feature Class \\
\hline \multicolumn{2}{|c|}{ 匀UoR_Campus2006 } & File Geodatabase Feature Class \\
\hline \multicolumn{2}{|c|}{ 國UoR_Campus2006_ft } & File Geodatabase Feature Class \\
\hline \multicolumn{2}{|c|}{ 圆UoR_Campus2007 } & File Geodatabase Feature Class \\
\hline \multicolumn{2}{|c|}{ (圆UoR_Campus 2010} & File Geodatabase Feature Class \\
\hline \multicolumn{2}{|c|}{ 国UoR_CampusBuildings } & File Geodatabase Feature Class \\
\hline \multicolumn{2}{|c|}{ OUoR_CampusHydrants } & File Geodatabase Feature Class \\
\hline$\because U_{0} R_{-}$ & CampusPoint & File Geodatabase Feature Class \\
\hline$\because$ UoR_ & CityHydrants & File Geodatabase Feature Class \\
\hline$\rightarrow$ UoR_ & CityWaterlines & File Geodatabase Feature Class \\
\hline$\because$ Uor_ & CityWaterServicePoints & File Geodatabase Feature Class \\
\hline$\because U_{0}$ & CommServiceAgenciesFall... & File Geodatabase Feature Class \\
\hline$\oplus$ UoR_ & Contourlft & File Geodatabase Feature Class \\
\hline 4 UoR_ & Contour5ft & File Geodatabase Feature Class \\
\hline$\because U_{0}$ & ElectricVaults & File Geodatabase Feature Class \\
\hline
\end{tabular}

\begin{tabular}{|c|c|}
\hline$\because$ UoR_FiberCableBoxes & File Geodatabase Feature Class \\
\hline$\triangle$ UoR_FiberCables & File Geodatabase Feature Class \\
\hline$\because$ UoR_fireAlarms & File Geodatabase Feature Class \\
\hline Uor_GuyWires & File Geodatabase Feature Class \\
\hline$\because$ UoR_OrangeGroves1909 & File Geodatabase Feature Class \\
\hline$\because$ UoR_OrangeGroves1911 & File Geodatabase Feature Class \\
\hline$\because$ UoR_Powerpoles & File Geodatabase Feature Class \\
\hline$\sqcup$ UoR_Railings & File Geodatabase Feature Class \\
\hline$\triangle$ UoR_Roads & File Geodatabase Feature Class \\
\hline (주)UoR_Roads1909 & File Geodatabase Feature Class \\
\hline 國UoR_RoadsLots & File Geodatabase Feature Class \\
\hline$\because$ UoR_SpotElevPoints & File Geodatabase Feature Class \\
\hline (1) UoR_StauferParkinglslands & File Geodatabase Feature Class \\
\hline UoR_Steps & File Geodatabase Feature Class \\
\hline YUoR_StreetLights & File Geodatabase Feature Class \\
\hline$\because$ UoR_TrafficPoints & File Geodatabase Feature Class \\
\hline$\because$ Uor_TrafficSignals & File Geodatabase Feature Class \\
\hline$\because$ UoR_TrafficSigns & File Geodatabase Feature Class \\
\hline$\because$ UoR_TrashBins & File Geodatabase Feature Class \\
\hline 廌UoR_Trees2003 & File Geodatabase Feature Class \\
\hline$\because$ UoR_Trees2006 & File Geodatabase Feature Class \\
\hline$\because$ UoR_TreesPoints2003 & File Geodatabase Feature Class \\
\hline$\because$ UoR_UtilityBoxes & File Geodatabase Feature Class \\
\hline 國UoR_Walkways 2003 & File Geodatabase Feature Class \\
\hline 國UoR_Walkways2005 & File Geodatabase Feature Class \\
\hline (⿶) UoR_WomenSoftballfield & File Geodatabase Feature Class \\
\hline 國UoR_ZanjaStreambed & File Geodatabase Feature Class \\
\hline 国UoRCampus_2010Dec & File Geodatabase Feature Class \\
\hline 國UoRCampus_20100ct & File Geodatabase Feature Class \\
\hline$\because$ UorCampus_20100ct_points & File Geodatabase Feature Class \\
\hline (UoRCampus_2011April & File Geodatabase Feature Class \\
\hline$\because$ UoRCampus_2011April_points & File Geodatabase Feature Class \\
\hline$\because$ UoRCampus_ParkingAccess & File Geodatabase Feature Class \\
\hline 國ZanjaStreambed & File Geodatabase Feature Class \\
\hline
\end{tabular}

Figure 5-2: The Redlands Institute Geodatabase File Structure. 
This review of data was critical before template population because this step provided the necessary guidance and expectations that the CMP mandated for this contribution. After review of the RI data, it was determined that the geodatabase provided the necessary University of Redlands data that was required by the CMP. However, some of the RI data that was provided did require some adjustments and renaming. These adjustments were minor and did not significantly hinder the progress of this project.

\subsection{Feature Class Selection, Preparation, and Population}

After reviewing Esri's template, the RI geodatabase, and organizing the data, the next step in creating the University of Redlands Campus Map was to select the first feature class for population. The idea behind selecting the first feature class for population was to provide a major outline or boundaries of the University of Redlands. Thus, the LandscapeArea was selected as the first layer for population. The LandscapeArea possessed all features on the campus: Grass, Mulch, Gravel, Rock, Ivy/Groundcover, Planter, Other, and Unknown. Because this layer covered so much area on the campus and outlined so many buildings and pavement areas, the University of Redlands campus immediately took shape.

Once this feature class was selected, there were additional considerations required before population of the LandscapeArea feature class, including: what were the required attributes for this feature class, how was this feature class to be imported into the template, and would this feature class later be broken into different feature classes in the map. Once these considerations were addressed, the template population commenced. 
The first step in populating the template was to add a field in the attribute table in both the RI data and the template Figure 5.3. This added field was named FeatureLinkID. The reason for this was to keep all attributes that the RI had assigned their data and later to join it to the template attribute table. This data, although more than required by the Community Maps Program, was too valuable to lose.



Figure 5-3: Adding “FeatureLinkID" Field to the Attribute Table.

Figure 5.4 shows that the value of the FeatureLinkID was calculated by setting it equal to the OBJECTID which already existed in both data sets. This was done in the RI attribute table and the template attribute table. 


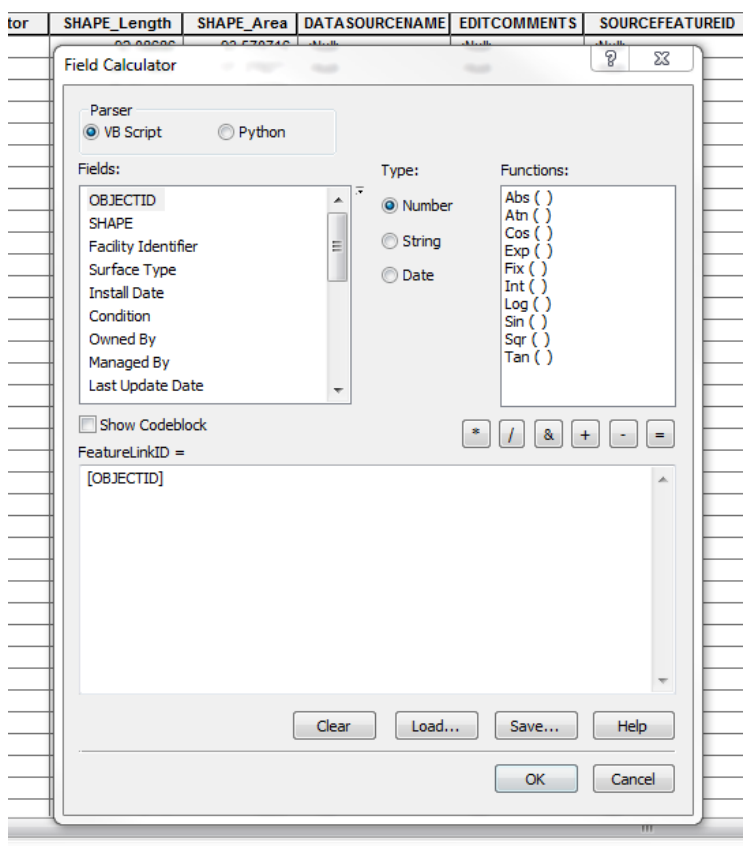

Figure 5-4: Populating the "FeatureLinkID" Field with the Field Calculator.

Again, assigning both the RI feature classes and the template a FeatureLinkID in the attribute table was essential. This created a common source (target) between the RI data and the template allowing for population into the template. Additionally, this was later used to join tables in the attribute tables. Figure 5.5 shows what the FeatureLinkID field looks like in the RI feature class attribute table. Note that this process for adding the FeatureLinkID field was also done for the template but is not shown in this document because no population had taken place into the template, only data selection and preparation. 


\begin{tabular}{|c|c|c|c|c|c|}
\hline OBJECTID_1* & FeatureLinkID & NAME & FEATURE & CATEGORY & ALIAS \\
\hline 1 & 1 & University Hall & Building & Academics & \\
\hline 2 & 2 & Truesdail Speech Center & Building & Academics & \\
\hline 3 & 3 & Thompson Aquatic Center & Athletic & Athletics & \\
\hline 4 & 4 & East Hall & Building & Residence Halls & \\
\hline 5 & 5 & Anderson Hall & Building & Residence Halls & \\
\hline 6 & 6 & Hedco Hall & Building & Academics & Hedco Hall for Biology and Chemistry \\
\hline 7 & 7 & Energy Center & Building & Facilities Management & Mechanical Center \\
\hline 8 & 8 & Health Center & Building & Administrative Offices & \\
\hline 9 & 9 & North Hall & Building & Residence Halls & \\
\hline 10 & 10 & Merriam Hall & Building & Residence Halls & \\
\hline 11 & 11 & Memorial Chapel & Building & Administrative Offices & \\
\hline 12 & 12 & Watchorn Hall & Building & Academics & \\
\hline 13 & 13 & Orton Center & Building & Administrative Offices & \\
\hline 14 & 14 & Fine Arts Building & Building & Theatres and Art Studios & \\
\hline 15 & 15 & Fairmont Hall & Building & Residence Halls & \\
\hline 16 & 16 & Melrose Hall & Building & Residence Halls & \\
\hline 17 & 17 & Williams Hall & Building & Residence Halls & \\
\hline 18 & 18 & Grossmont Hall & Building & Residence Halls & \\
\hline 19 & 19 & Armacost Library & Building & Administrative Offices & \\
\hline 20 & 20 & California Hall & Building & Residence Halls & \\
\hline 21 & 21 & Bekins Hall & Building & Residence Halls & \\
\hline 22 & 22 & Irvine Commons & Building & Dining on Campus & \\
\hline 23 & 23 & Hunsaker University Center & Building & Administrative Offices & \\
\hline 24 & 24 & Gregory Hall & Building & Academics & \\
\hline 25 & 25 & Founders Hall & Building & Residence Halls & \\
\hline 26 & 26 & Currier Gymnasium & Athletic & Athletics & \\
\hline 27 & 27 & Willis Center & Building & Administrative Offices & \\
\hline 28 & 28 & Larsen Hall & Building & Academics & \\
\hline 29 & 29 & Hall of Letters & Building & Academics & Sara Grace Parker Hall of Letters \\
\hline 30 & 30 & Duke Hall & Building & Academics & \\
\hline 31 & 31 & Administration Building & Building & Administrative Offices & \\
\hline 32 & 32 & Hornby Hall & Building & Academics & \\
\hline 33 & 33 & Alumni House & Building & Administrative Offices & \\
\hline 34 & 34 & Frank E. Gannet Center & Building & Academics & Gannett Center \\
\hline 35 & 35 & Pi Chi House & Building & Apartments and Houses & \\
\hline 36 & 36 & Kappa Siqma Siqma House & Buildina & Apartments and Houses & Bird House \\
\hline \multicolumn{5}{|c|}{  } & \\
\hline 0 & 䒠| & 0 out of 268 Selected) & & & \\
\hline
\end{tabular}

Figure 5-5: Populated "FeatureLinkID" Field in the Template Attribute Table.

The previous figures illustrate the steps in preparing this data for population and joining the attribute tables by way of a common field (FeatureLinkID). This was essential for populating the template and joining attributes to maintain and provided additional campus information. These steps follow the Esri workflow for template population. Once data preparation was completed, it was finally time to begin template population could begin.

After data review and data preparation took place with the RI data and the template data, it was time to populate the template and create the first feature class in the University of Redlands Campus Map. As stated earlier, LandscapeArea was the selected feature class for population. Because athletic fields are mostly comprised of vegetation and soil, it was the first feature class populated in the LandscapeArea feature class. 
Figure 5.6 illustrates how the first step in how the Athletic Fields Feature Class was loaded into the LandscapeArea feature class residing in the template.

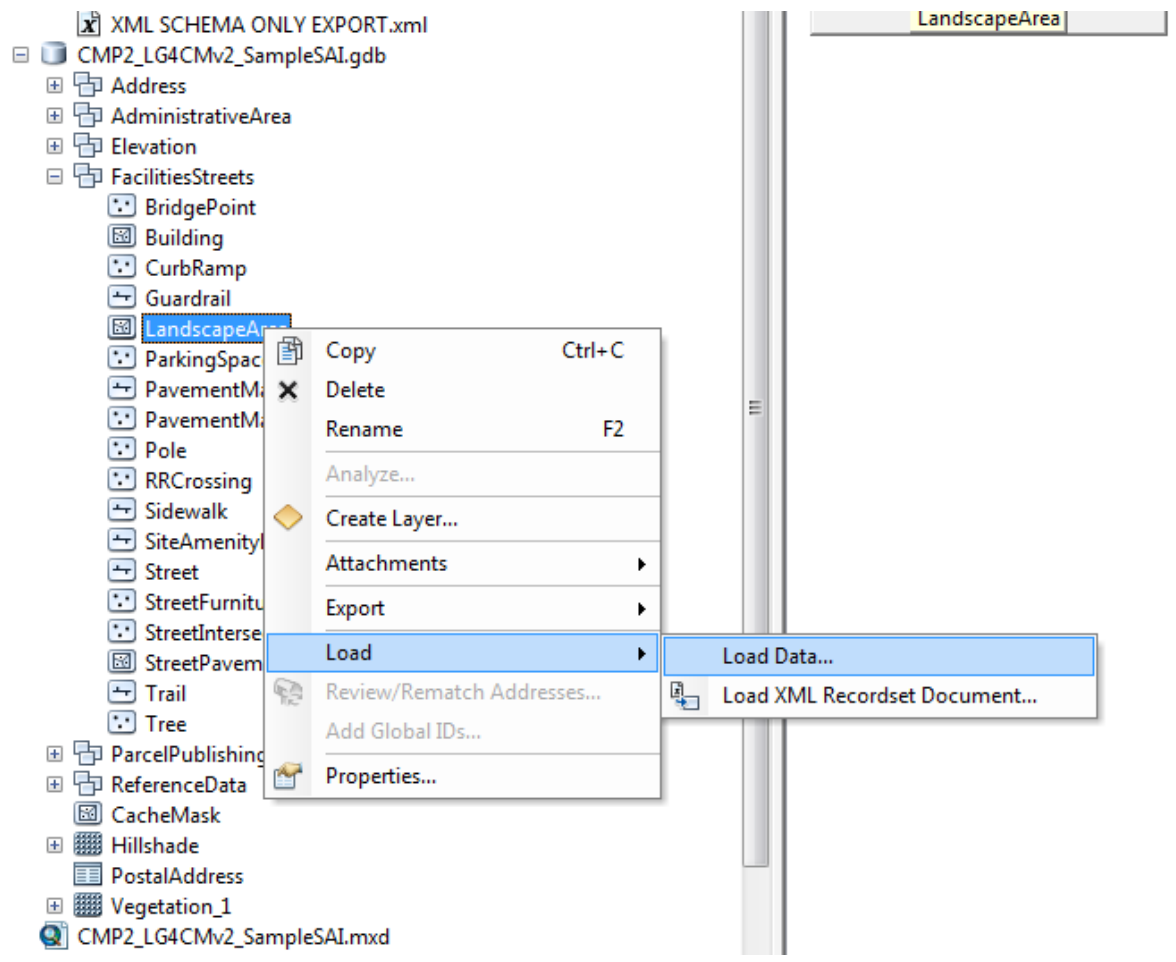

Figure 5-6: Loading Data into the Template From the Redlands Institute Data.

Loading data in the template took place in ArcCatalog as opposed to ArcMap because data would not load sufficiently in ArcMap. The next step, illustrated in

Figure 5.7, requires the input of source data in the dialog box. The source data as stated earlier was provided by the RI. 


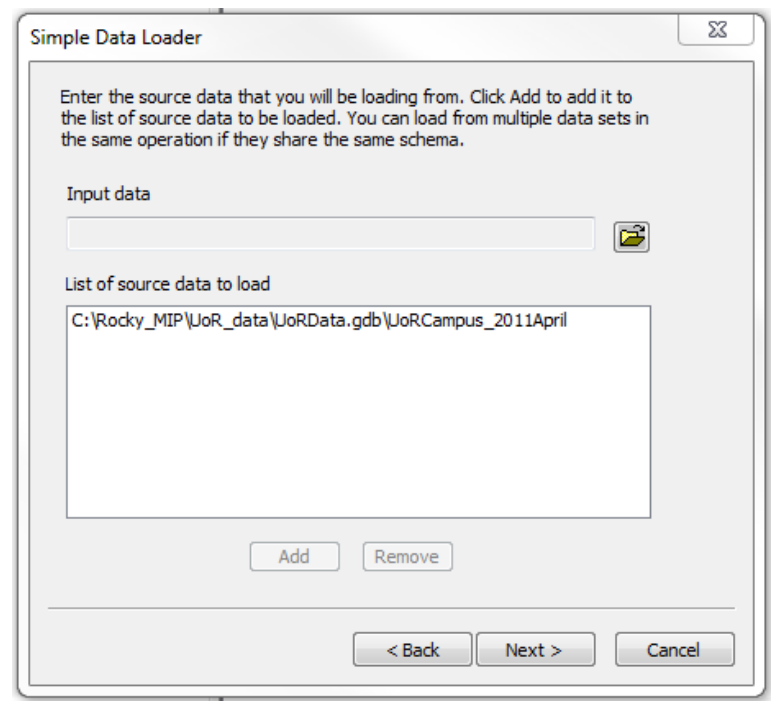

Figure 5-7: Loading Data into the Template Using the Simple Data Loader.

The subsequent dialog box prompted the selection of an existing geodatabase in which the input data would populate the template. During this step it was very important to select the option "I do not want to load all features into a subtype." This can be seen in Figure 5.8.

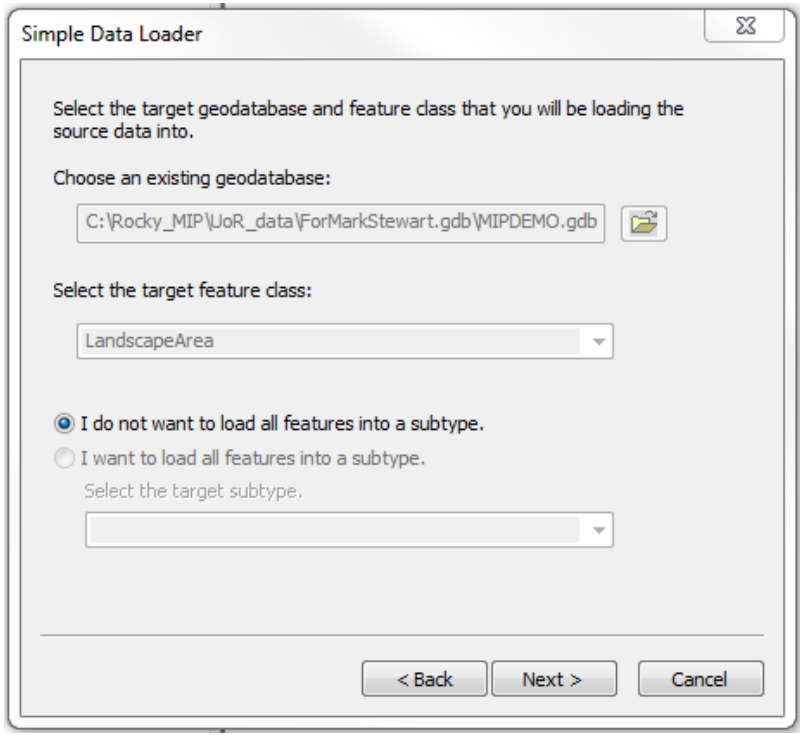

Figure 5-8: Loading Data into the Template Using the Simple Data Loader. 
There were many Target Fields and Matching Source Fields between the two data sources, as seen in Figure 5.9. Because so many GIS professionals create their own data according to their own preferences, it was easy to understand why a common field was needed to be created for data matching within the two data sources:

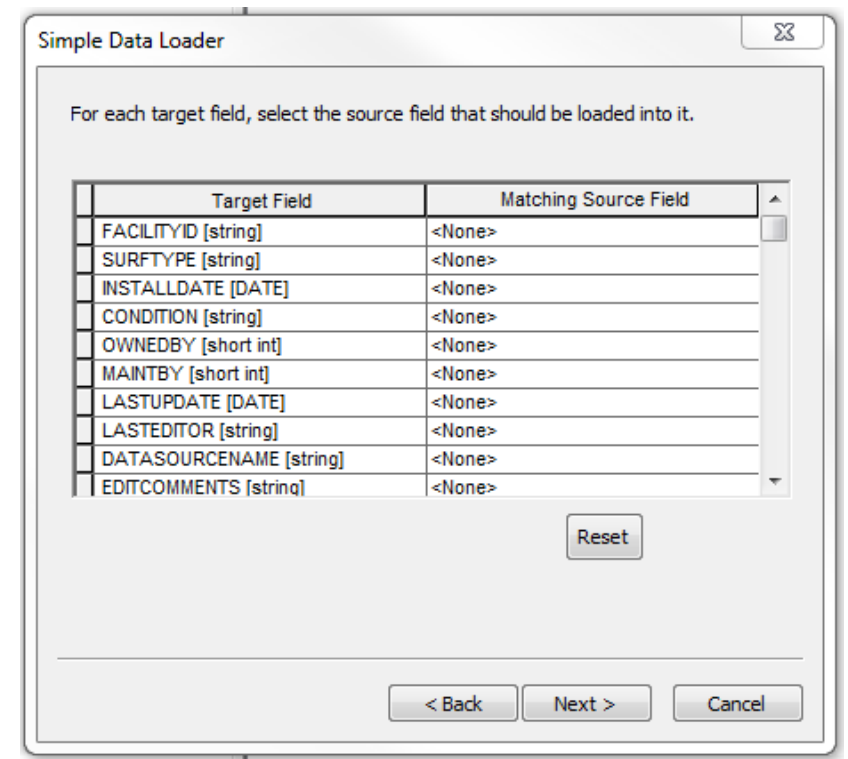

\section{Figure 5-9: Setting Target Fields in the Simple Data Loader.}

Additionally, notice in Figure 5.9 and Figure 5.10 how many Target Fields there are. This is why FeatureLinkID was created in both attribute tables. When creating this common source field, the user knows exactly which field to look for, eliminating time inefficiency searching through the fields. During this step in loading the RI data into the template, it was time to utilize the created attribute field FeatureLinkID. This common source name created the target for the two data sources to link together and to populate the template as seen in Figure 5.10. 


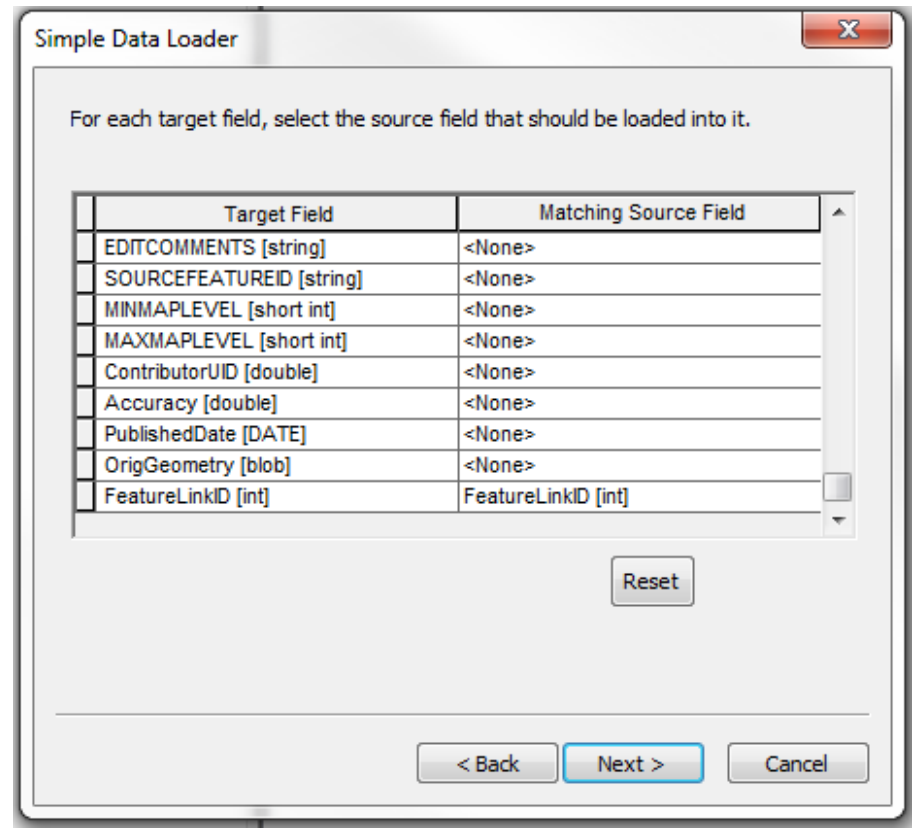

Figure 5-10: Setting Target Fields in the Simple Data Loader Using FeatureLinkID.

The final step in loading the Athletic Fields Feature Class from the RI data into the LandscapeArea Feature Class in the template was to build the query that satisfied the specific feature in the section of template population. By setting the Feature to Athletic (Figure 5.11), this satisfies the selected feature class population for this section. It was also important to select "Load only the features that satisfy a query." This was done because only Athletic Fields were selected to be input into the LandscapeArea feature class in the template. 




Figure 5-11: Loading Data Using Query Builder.

The resulting processes revealed the very beginning of the campus map, the Athletic Fields (Figure 5.12), which set the basic outline of the University of Redlands Campus Map. 


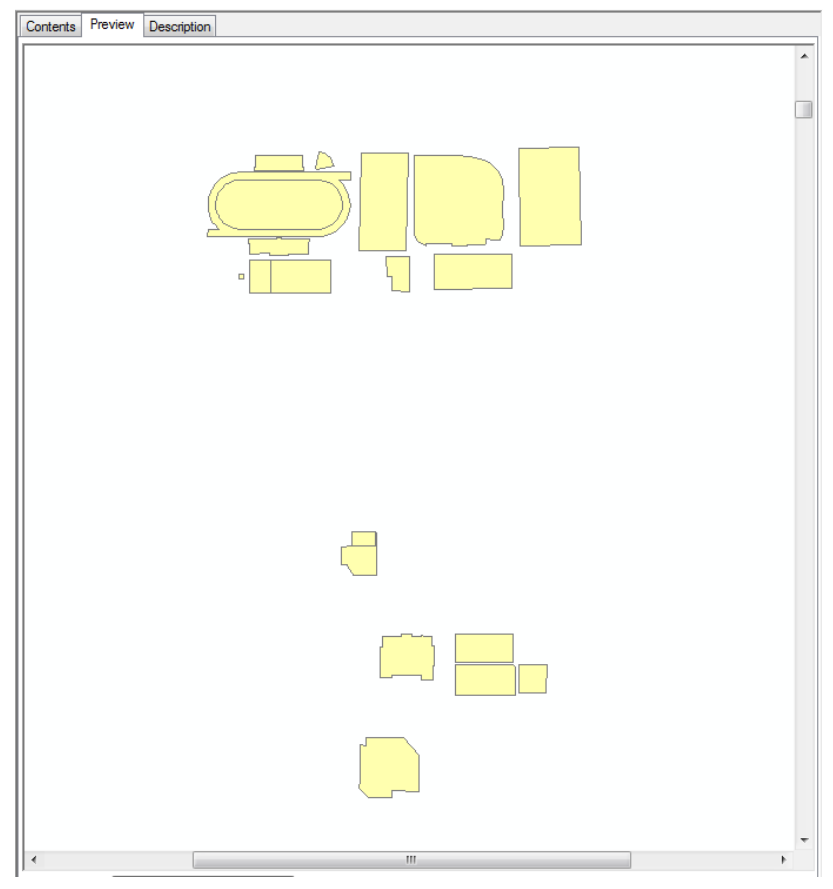

\section{Figure 5-12: Athletic Fields Layer.}

Loading the Athletic Fields was a great start in the populating of LandscapeArea in the template, however there were more feature classes in the RI data that fell under the LandscapeArea feature class in the template. Figure 5.13 shows these additional features, which included: Garden, Grass, and Groves. 


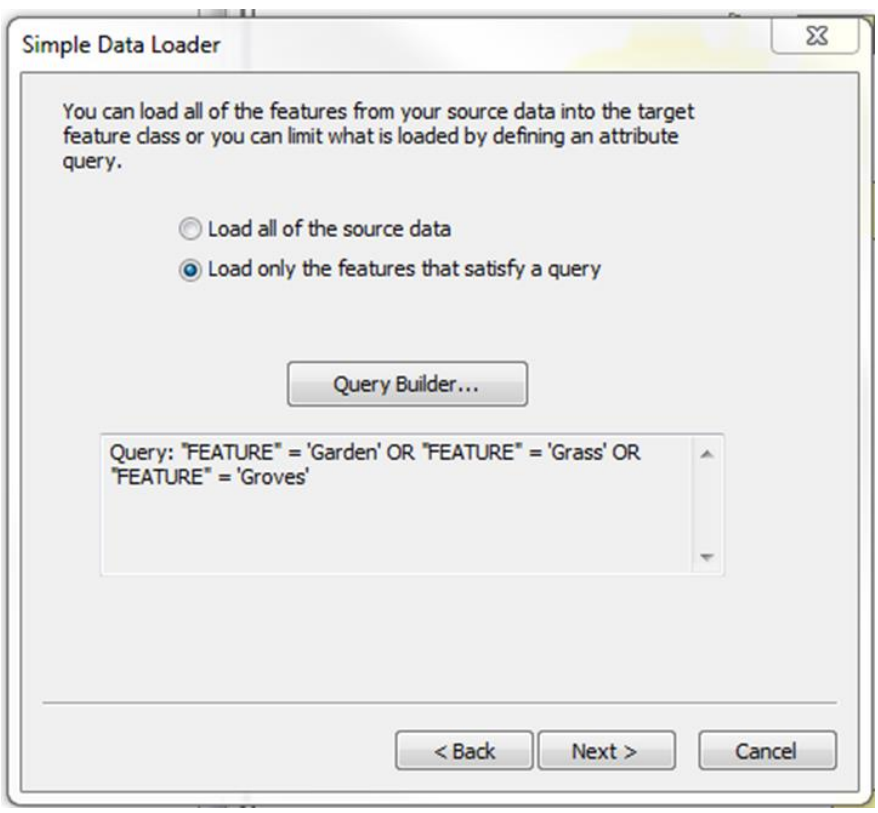

Figure 5-13: Loading Data Using Multiple Definitions in Query Builder.

Therefore, the process of loading data into the template in ArcCatalog was necessary in completing the LandscapeArea feature class. These processes were done again to complete the population of the LandscapeArea feature class. Figure 5.14 shows the outcome of that process. 


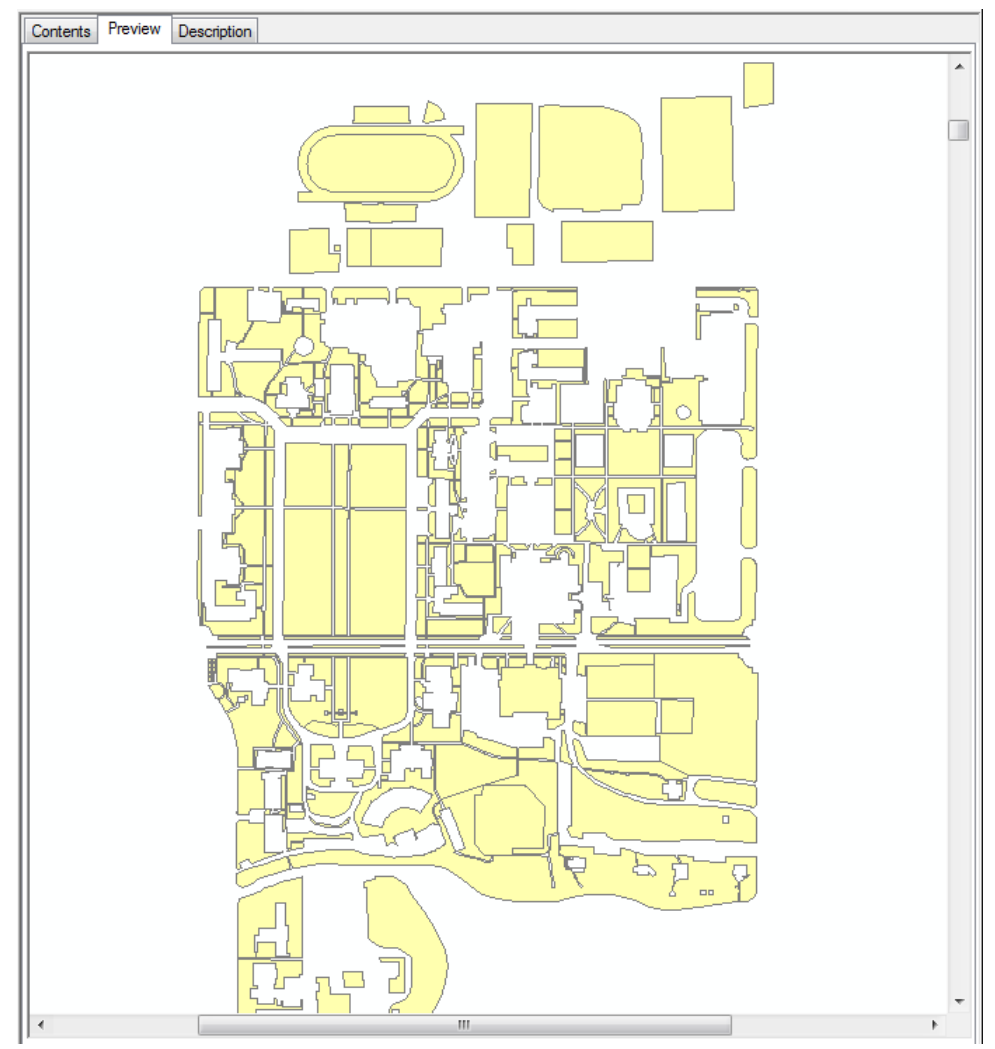

Figure 5-14: Layer Output From Definition Query.

Once the RI data were loaded to the template, the shape of the University of Redlands took form. Additionally, the previous fields that were created in the attribute tables of the RI data and the template data were joined, keeping all of the necessary attributes required in the template and those additional attributes provided by the RI. These processes were repeated for the remaining required layers: Trees, Pavement, Buildings, Water Features, Sports Fields, and Sports Courts, as seen in Figure 5.15. 




Figure 5-15: Required Layers Satisfying Template Demands Using Data Loader.

\subsection{Joining Attributes Between Data Sources}

As stated earlier, the FeatureLinkID attribute field was created in the RI data and the template. Once the LandscapeArea feature class was populated in the template, joining the attributes of these features that were created by the Redlands Institute was necessary. The template requires its attributes to be populated with source data attributes.

Additionally, it was expressed by Mark Stewart that the RI attributes were too valuable to lose. The additional attributes, although not required by the template, were included in the LandscapeArea Attribute Table. The FeatureLinkID field was used to join these attributes. Figure 5.16 shows the Join Field tool in the Data Management Toolbox. Joining the attribute tables allowed for only specific fields to be joined. This was done by reviewing all the attribute fields between the RI data and the template. The review was 
necessary before selection because not all GIS users use the same naming conventions.

Finally, during selection all fields were selected except: Feature, Shape Length, Shape

Area, and FeatureLinkID. These attributes were left unchecked because these fields were already accounted during the population of the LandscapeArea Feature Class.

Eliminating duplicate fields saved time during the geodatabase clean-up.

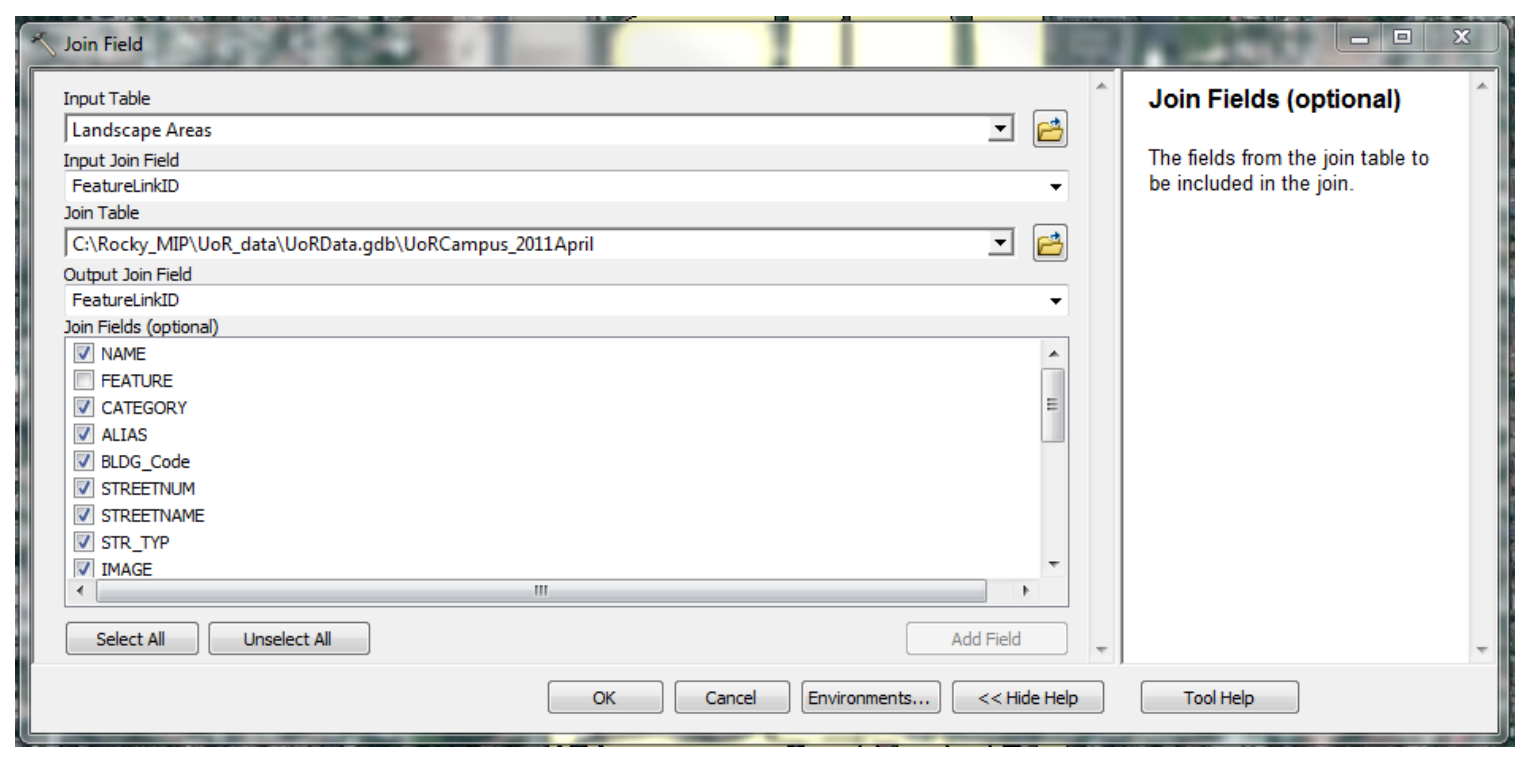

Figure 5-16: Joining Fields to Keep RI Data Along With Template Data.

\subsection{Campus Map Quality Assurance with Minor Adjustments}

Once the University of Redlands Campus map was created, there were a few minor fixes.

It was necessary to digitize parking lines, add markings on the football field, provide foul lines for the baseball and softball fields, and add handicap markings for the parking lots.

These additions gave the campus map the detail that Esri's Community Maps Program wished to achieve. These additions, although minor, did require additional time, but ensured a happy client in Mark Stewart. Figure 5.17 shows the finished University of Redlands Campus Map. The map was then turned over to Mark Stewart for quality assurance and published as a Community Map. 


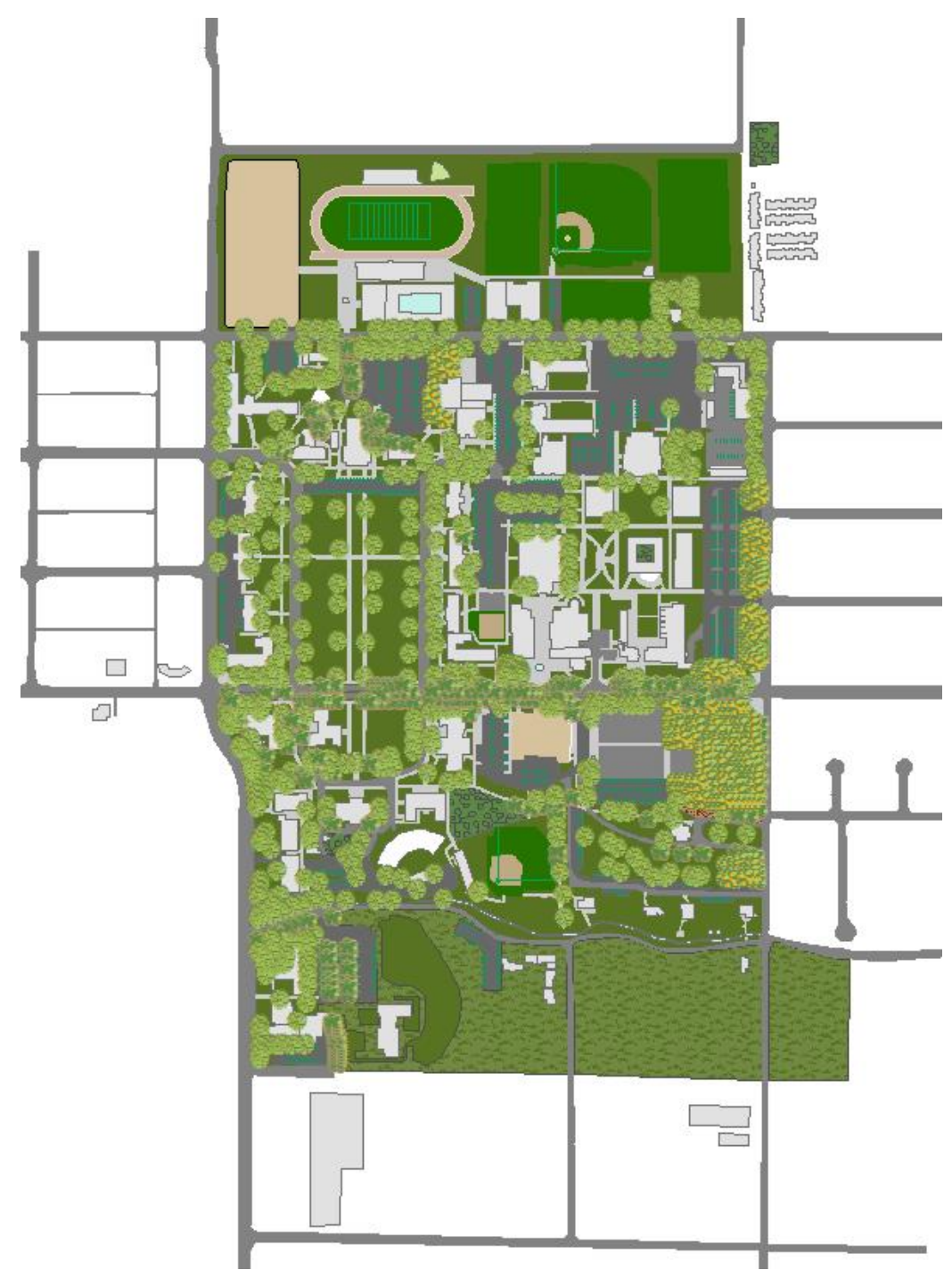

Figure 5-17: Final Output Resulting The University of Redlands Campus Map.

\subsection{Geodatabase Quality Assurance}

Once the U of R Campus Map was created, the geodatabase was reviewed. The Esri template expedited this process because the geodatabase structure was provided.

Duplicate attribute fields were deleted and null values addressed. The geodatabase was populated with additional attributes that were not required by the template. These additions were discussed with Mark Stewart and deemed satisfactory to maintain. 


\subsection{Geodatabase Filter and Update Tool}

At the beginning of the project, it was established that a tool would perform two functions within the $\mathrm{U}$ of $\mathrm{R}$ Campus Map Geodatabase: to filter out any data that where considered private or institutional data, and only allow for the use of public data. The data received from the RI contained nothing that was considered private. No information on students, student housing, or classrooms was provided. Because no private data were provided, there was no need for the creation of a tool that provided a filter function. Regarding the update function, there was no established party to provide updates to the $\mathrm{U}$ of R Campus Map hosted by the Community Maps Program. With that being said, there is no ModelBuilder tool that provides updates to the $\mathrm{U}$ of $\mathrm{R}$ Campus Geodatabase.

\subsection{Summary}

This chapter discussed the processes necessary in completing this project, including the RI data and template review, data selections, preparation, and population. This chapter also included joining attributes between data sources, map quality assurance and necessary minor adjustments, and $\mathrm{U}$ of $\mathrm{R}$ geodatabase quality assurance. Finally, this chapter discussed the design and function of the $\mathrm{U}$ of $\mathrm{R}$ geodatabase tool. The University of Redlands Campus Map was created with the use of the Local Governments Template and followed the provided workflow. This ensured that the map was created satisfactory to the standards set by the client. The resulting $\mathrm{U}$ of $\mathrm{R}$ Campus Map is now hosted for public use by the Community Maps Program on ArcGIS Online. 


\section{Chapter 6 - Results and Analysis}

This chapter explains the results and analysis in completing the $\mathrm{U}$ of $\mathrm{R}$ Campus Map for the Community Maps Program at Esri. The resulting Campus Map was the goal of this project and this chapter will analyze the processes of that achievement.

\subsection{Analysis of the RI Data and Template Data}

One of the first challenges discovered with the RI Data was that all the features were created as a single shapefile as seen in figure 6.1. This is because the campus map was created as a single shapefile approximately 10 years ago in a GeoDesign class.

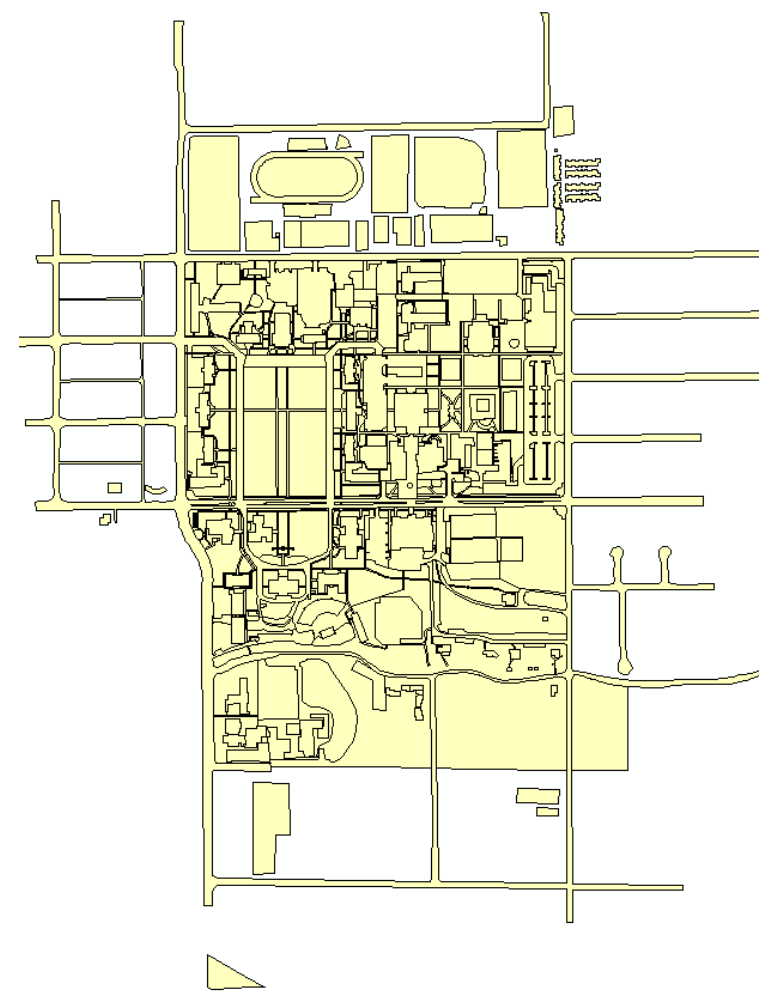

Figure 6-1: University of Redlands Campus as source data from Redlands Institute.

This initially was thought to be a considerable time concern because each feature had to be queried out into individual feature classes for population into the template. Once the 
data was loaded into the individual feature classes in the template, a new concern arose. The concern was that the features did not align with the aerial imagery that was used as a basemap background. The issue with the features not aligning was not a projection or geo-referencing issue, but rather because the use of shapefiles did not allow for topology rules. Had this been created as feature classes with topology, rules may have been set to ensure accurate geometric relationships. However, this process was not necessary for the use of the RI's needs or Esri’s Community Maps Campus Map. At that point the option to remedy this situation was to then edit the vertices of the individual features, move features in an editing session, and assign two features topology. The first feature that was selected to have vertices edited was the parking lots. As the parking lots began to become accurate and align with the background basemap, it was realized that the features were no longer sharing boundaries with neighboring features. Parking lots that were touching grass features or building features began to have space between the features. This began to provide an idea as to why the source data was all created under a single feature class. By creating a single feature class, features will always share a common border. One solution to remedy the creation of a single feature class, would be to create individual features and set topology rules. However, the immediate concern may be that if features are being digitized by interns, do these interns understand or poses the necessary knowledge of topology. Therefore, the most simplistic remedy is to create the individual features under a single feature class and assign them the appropriate symbology and attributes.

After initial loading of data the template became corrupt and was unusable. To date, no certain answer can be given as to why the template became corrupt and failed to allow 
any feature to be created or manipulated. This occurred at the Esri facility while working with Mark Stewart. The fortune of this happening at Esri meant that Mark could witness this first hand and begin to see some of the frustrations and complications with contributors in the community maps program. Again, to date it was unclear if the template had an underlying issue or if it was user error.

\subsection{Symbology: Default or Decision}

Once the template was loaded with the source data, the University of Redlands took its shape. Unfortunately, it was obvious that the template was not designed for such a large scale map. The Local Government Template is designed for smaller scale maps that do not zoom in on the details as much as the campus map required. The first instance that was noticed where the default symbology was in the athletic grass symbology. The grass was grass that one would expect to see in a map of the everglades. Figure 6.2 shows the default athletic grass symbology on the left and the altered athletic grass symbology on the right.
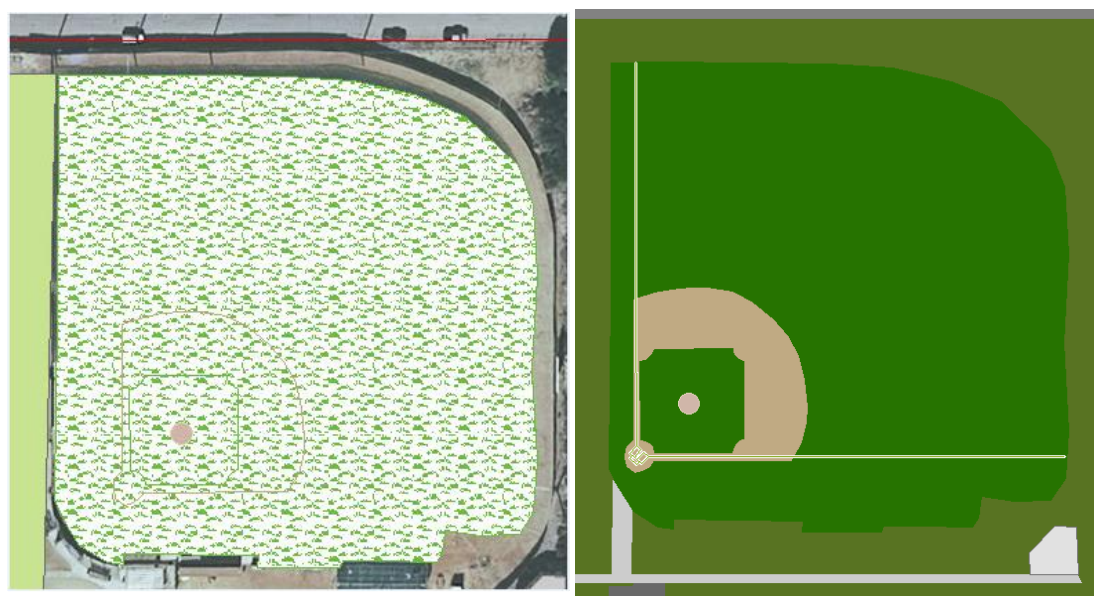

Figure 6-2: Default Symbology vs. Decided Symbology 
The decision to alter the default symbology was based on making the map more appealing to the map reader. Additionally, it was observed numerous campuses that have contributed their maps to the Community Maps Program have mad the same decision to not follow the default symbology in various other applications. This was necessary in creating the football field, softball field, soccer field, and practice fields. The template was meant as a guideline, a guideline that should rarely be ventured from. However, it does allow for changes, especially in times of necessity as in the need regarding the campus map. Had the template allowed for so much flexibility, the University of Redlands Campus map would not have looked as aesthetically pleasing or cartographically correct.

In addition to the symbology selected for the Athletic Grass features, were the symbology representation for the trees layer that was added to the campus map. This feature class was represented with points from the Redlands Institute. It was necessary in ensuring that the very trees that help in defining the University of Redlands were represented to do so. It was crucial to include the palm trees that line the campus and Colton Avenue and it was even more important to represent the Orange Trees on campus that both the University of Redlands and the City of Redlands are known for. Some of the tree values were null in the attribute table, therefore it was necessary to ground truth some of these trees by walking the campus. Figure 6.3 shows the trees and their specific variety represented accurately on the campus map. 


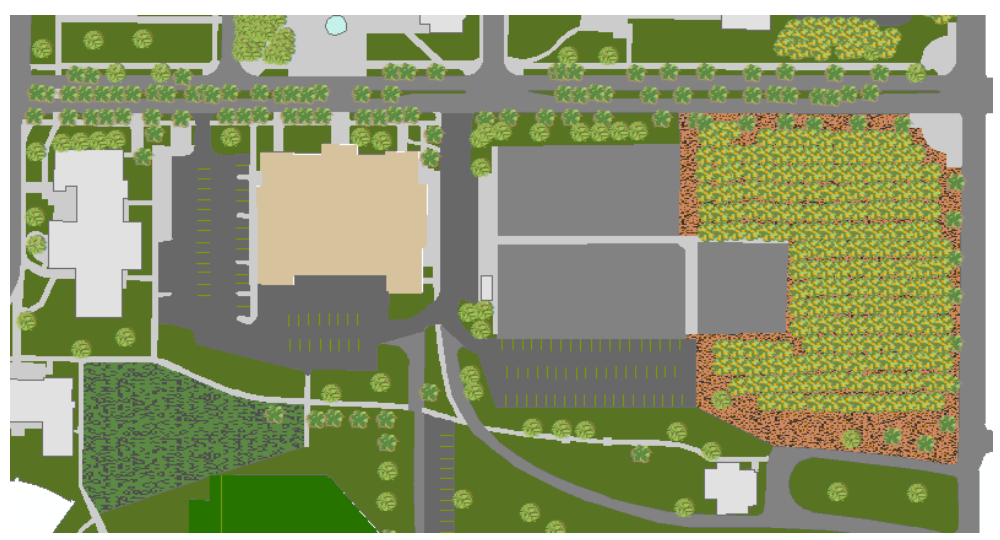

Figure 6-3: Tree representation.

\subsection{Creating Lines and Zoom Challenges}

In an attempt to give the University of Redlands Campus map more character, additional detail was necessary. The decision to add parking lot lines, football field marker lines, baseball field lines, and softball field lines was made toward the end of the campus map making process. This was because no source data was provided in any of these areas and the time necessary in creating these lines was exceptional. A challenge arose before any digitizing even occurred. When zooming in past 1:500, both the template and the imported basemap would disappear. This meant that digitizing from a source was only able to be done at 1:600 or larger. Therefore, much of the digitizing is only as accurate as possible from 1:600. Very fine details were at best valiant attempts of accuracy from zooming in and remembering the image. So without the capability to zoom in past 1:600, lack of source data, and occasional challenges from template complexity, the digitizing of the parking lot lines was the first obstacle tackled in this process of adding lines to the map. These lines were placed as additional detail but do not truly reflect the actual and specific placement or quantity of parking lot lines. However, the location of parking lots 
is accurate. This process took approximately seven hours to complete. Figure 6.4 shows the detail added to the campus map with the added parking lot lines.

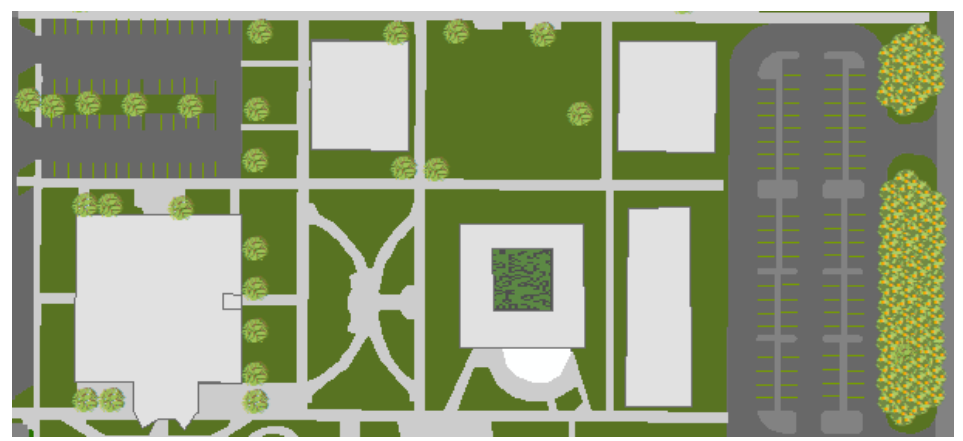

Figure 6-4: Parking lot lines digitized for added detail.

The next sets of lines to be digitized were the baseball field, softball fields, and football fields. Again, there was no source data that were available for these lines. Additionally, the same zoom limitations hindered the processes and accuracy in creation of the parking lot lines. The difference was the attempt to create these as digitized lines and then perform a graphics to features function. The concern with creating graphics and then converting them to features is that the map contributor must ensure two functions occur. The first was that the created lines point to the specific feature dataset, if not, they would not show on the map. The feature would be created; however, it would not show on the map but would in the created features window. Second, the contributor needed to ensure that the created graphics take the feature symbology. The graphic would appear even if it was not a feature giving the false sense that it was created, but when the map changes extents, the graphic would not change with the map. Figure 6.5 shows the finalized process of the digitized lines for the football field and the baseball field. 


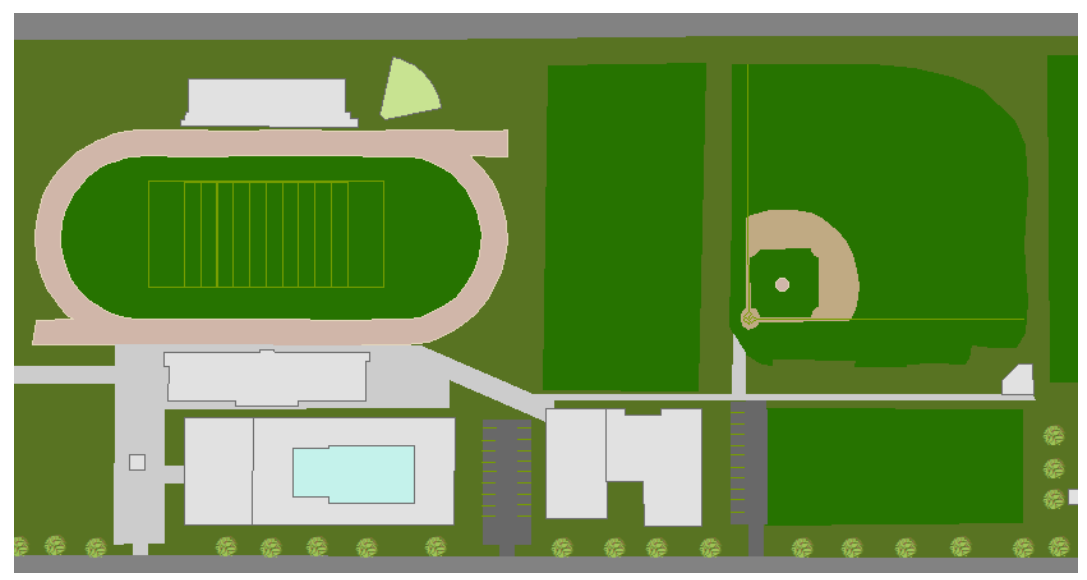

Figure 6-5: Digitized football field and baseball field playing lines.

\subsection{Summary}

All the previously mentioned processes and challenges in this chapter were documented, reported, and in some cases witnessed by Mark Stewart of the Community Maps Program at Esri. As stated before, some of these issues were unknown, possible user error, template complexity, or software limitation. The available flexibility to the template allowed for some work-a-rounds and symbology changes. Since the beginning of this project until its end, there were two templates used, an older template and an updated template. For smaller scale maps such as the University of Redlands Campus map, it is good to understand the limitations of the Local Government Template in regards to how it will be used. Finally, new changes and updates have continued to occur to the templates that are used in the CMP at Esri. 



\section{Chapter 7 - Future Works and Conclusion}

Since the inception of the Community Maps Program in 2010, there were an estimated 600 participants to date. The Community Maps Program can only be as successful as it authoritative contributors make it, which means that more contributions and annual updates are necessary for to maintain and further build a successful Community Maps Program on ArcGIS Online. The contribution of a community map of the University of Redlands was produced and contributed to further populate the Community Maps Program by Esri. Although this contribution adds to the success of this initiative by Esri, this chapter will layout future works that could maintain the success of this contribution.

\subsection{Future Work for the Community Maps Contribution}

The Community Maps Program has a desire for all contributions to be updated annually. These updates are requested to be maintained by the authoritative source that created them; unfortunately, this would require additional labor hours by the contributor that employers do not wish to offer or donate. The solution to this would be an update tool that would provide updates to the geodatabase. This tool was originally purposed for creation during this project, but project completion time was the deciding factor for this tool to find its way into this chapter of the report. This tool could be written in Modelbuilder and would most likely be the most efficient way to provide updates to the geodatabase.

\subsection{Future Work for the Redlands Institute}

One concern during the completion of this project was that data considered private or institutional may be released to the public during the construction and contribution of the 
campus basemap of the University of Redlands. This would most likely have been done in the form of attribute data in the geodatabase being used or joined in the data loading of the source data to the template data. The solution to that concern could be to create a tool that runs through the source geodatabase and eliminates data that is considered or labeled private or institutional. This tool was planned to be created during this project, but two factors eliminated the need during this project: project completion deadline and no data fit that description from the source data. There is a Delete Field tool in Arc10 that may fit the needs a one-time contributor, however once this tool runs, the field cannot be brought back from deletion. Additionally, this tool may not prove to be as efficient for annual updates as the Delete Field and would most likely require the contributor to have to manually check source data for criteria considered private or institutional.

Another future work could be the contribution of Topology rules to the source data that was provided by the Redlands Institute. It was discovered during the review of source data while population of the Local Government Template. Although neither the Community Maps Program nor the Redlands Institute necessitate the usage of Topology rules in their data or uses, this lack of rules did create hardship in digitizing of features and details on the campus map of the University of Redlands. The source data was actually a single shapefile created approximately 10 years ago which meant that any update that was created, was done so by cutting polygons or editing vertices. This practice continued over the course of these 10 years and created unnecessary added time during the digitizing and editing of features in the campus map. Adding these topology rules may eliminate the inefficiency of campus edits in the future. 


\subsection{Future Work for the Community Maps Contribution}

During the construction of the University of Redlands Campus map, challenges in symbology and digitizing were encountered. This is primarily due in part that the campus map uses the Local Government Template for the Community Maps Program. This template is currently the smallest scale used in the production of campus maps. Unfortunately, this template is good, but could be better. The reason for its short fall deals with the fact that at this scale, detail is often not fully allowed. To be specific, digitizing at any scale smaller than 1:600 is virtually impossible because the source data or basemap in which digitizing is being based off of, disappears. This means that digitizing lines such as parking lot lines becomes more of a calculated estimation of actual location of lines. Additionally, the symbology becomes cartographically unappealing because when zoomed at a 1:600 scale, the level of detail becomes so great that athletic grass appears more as marsh or swamp. The template recognizes this shortfall and allows for flexibility in the template to alter symbology, but this is not user friendly and does not create an appealing experience for a first time contributor.

Another challenge for the Local Government Template in the Community Maps Program is pathway of features in the Local Government Template Geodatabase. An example of this is the baseball lines and football lines features that were created in the campus map. These features point to the Pavement Marking Lines feature in the geodatabase. This does not make sense, but it is not entirely wrong. This is once again due to the fact that the Local Government Template is the smallest scale template available, but not a small enough template to provide for the necessary detail of a campus map. At this time, this is the best available template. Therefore, instead of recreating a 
new template for campus maps, the Community Maps Program Template designers have chosen to simply point these line features of any creation to the Pavement Marking Lines Feature. A solution to these digitizing, symbology, and features pointing to confusing feature classes and feature datasets in the geodatabase, may be to create a template that is specific to the needs of campus maps.

\subsection{Conclusion}

Change is never easy. So needless to say, to implement a new idea or policy is going to take time. In the case of using basemaps, the benefits are exponential if the use of basemaps is acceptable. Not all analysis can be used, but if basemaps can be used instead of recreating the same MXD time and time again, then by all means use them. Taking advantage of these basemaps will eliminate reduplication efforts. Secondly, creating these basemaps provide a common ground for GIS users to come up with new GIS and mapping ideas. These new mapping ideas may be exactly what are needed for the next big GIS or analysis idea. To begin implementing this, users should be urged to visit ArcGIS Online Community Maps. Here, GIS users will see some of the map ideas that other professionals are using or coming up with. Second, GIS users will be urged to add a basemap to their next MXD as a basemap layer. This will show the user that there are many maps to choose from and that if they don't like the map, they can simply turn off the layer or remove the layer.

The completion of this University of Redlands Campus Basemap coupled with future works suggested in this chapter, the campus map provided to the Community Maps Program will prove to be an effective, accurate, up-to-date, and efficient basemap for GIS professionals to utilize. Additionally, a recommendation will be for the Redlands Institute 
to utilize the new campus basemap for their daily use. Then additional operational layers can be used for facility management, student enrollment, etc. Then possibly in the future, each department can update their own operational layers which may include;

construction, maintenance, and student enrollment. This would ensure the most up to date data. Additionally, the update tool that will be provided to the Redlands Institute may ensure that annual updates are performed to the University of Redlands Campus Basemap that is hosted at ArcGIS Online. 



\section{Works Cited}

(2008). Geospatial Services and Applications for the Internet. New York: Springer.

Brewer, C. (2005). Designing Better Maps: A Guide for GIS Users. Redlands, California: Esri Press.

Brewer, C. (2008). Designed maps: A Sourcebook for GIS Users. Redlands, California: Esri Press.

Fu, P., \& Sun, J. (2011). Web GIS: Principles and Applications. Redlands, California: Esri Press.

Harder, C. (1998). Serving Maps on the Internet: Geographic Information on the World Wide Web.

Redlands, California: Esri Press.

Kerski, J., \& Clark, J. (2012). The GIS Guide to Public Domain Data. Redlands, California: Esri Press.

Knapp, C. (2003). Making Community Connections. Redlands, California: ESRI Press.

Pamuk, A. (2006). Mapping Global Cities: GIS Methods in Urban Analysis. Redlands, California: Esri Press.

Tomlinson, R. (2011). Thinking about GIS: geographic information system planning for managers. Redlands, California: Esri Press.

Stewart, M. (Personal Communication, November 17, 2011 - June 5, 2012)

United Nations. (1998). GIS Standards and Standardization; A Handbook. New York. 


\section{Appendix A. Important but Extraneous Information}

Put information and/or data here that are extraneous to your document. All of the content and the formatting of the Appendices should be discussed with and agreed upon by your committee chair. 